\title{
Aluminum-Assisted Densification of Cosputtered Lithium Garnet Electrolyte Films for Solid-State Batteries
}

\author{
Jordi Sastre, ${ }^{*},, \S \odot$ Tzu-Ying Lin, ${ }^{\dagger, \S \odot}$ Alejandro N. Filippin, ${ }^{\dagger}$ Agnieszka Priebe, ${ }^{\ddagger \odot}$ Enrico Avancini, ${ }^{\dagger \oplus}$
} Johann Michler, ${ }^{\dagger}$ Ayodhya N. Tiwari, ${ }^{\dagger}$ Yaroslav E. Romanyuk, ${ }^{\dagger}$ and Stephan Buecheler ${ }^{\dagger \oplus}$

\begin{abstract}
${ }^{\dagger}$ Laboratory for Thin Films and Photovoltaics, Empa-Swiss Federal Laboratories for Materials Science and Technology, Überlandstrasse 129, CH-8600 Dübendorf, Switzerland

${ }^{\ddagger}$ Laboratory for Mechanics of Materials and Nanostructure, Empa-Swiss Federal Laboratories for Materials Science and Technology, Feuerwerkerstrasse 39, CH-3602 Thun, Switzerland
\end{abstract}

\section{Supporting Information}

ABSTRACT: Garnet $\mathrm{Li}_{7} \mathrm{La}_{3} \mathrm{Zr}_{2} \mathrm{O}_{12}$ (LLZO) is a promising solid-state electrolyte due to its wide electrochemical stability window and high Li-ion conductivity. This electrolyte has potential to be employed in the form of thin films for solidstate batteries, a promising approach in the quest for safer batteries with higher energy densities at lower fabrication costs. In this study, we use a scalable cosputtering process to fabricate LLZO thin films with subsequent postannealing at a temperature of $700{ }^{\circ} \mathrm{C}$, significantly below the sintering temperatures employed in ceramic pellet processing. We

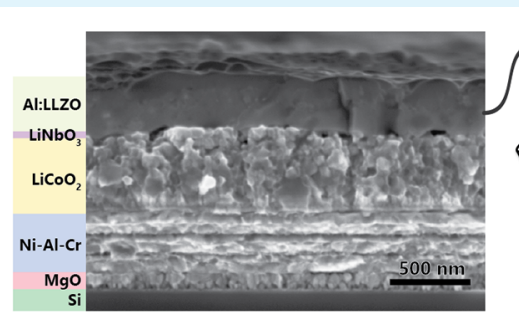
Cosputtered LLZO

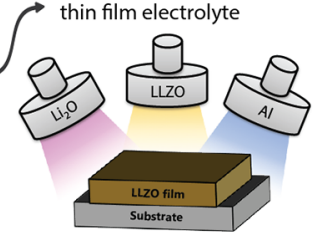
investigate the roles that $\mathrm{Li}$ excess and incorporation of $\mathrm{Al}$ play in the film's crystalline phase, microstructure, phase stability, and, ultimately, ionic conductivity. Our results reveal that improving the conductivity of LLZO thin films requires not only the stabilization of the cubic phase but especially the densification of the film and the minimization of the proton exchange degradation mechanism in the presence of moisture and $\mathrm{CO}_{2}$. These issues can be mitigated by effectively controlling the amount of $\mathrm{Li}$ and incorporating $\mathrm{Al}$ as sintering agent. An ionic conductivity at room temperature of $1.9 \times 10^{-5} \mathrm{~S} \mathrm{~cm}^{-1}$ was achieved with a $400 \mathrm{~nm}$ Al-substituted LLZO thin film. Finally, we prove that these LLZO thin films can be successfully deposited and crystallized on a $\mathrm{LiCoO}_{2}$ cathode.

KEYWORDS: LLZO, thin film, solid electrolyte, solid-state batteries, ionic conductivity, Al-assisted densification, LLZO protonation

\section{INTRODUCTION}

Current state-of-the-art LIBs, based on liquid electrolytes, seem to be reaching a technological limit in terms of energy and power density. All-solid-state lithium batteries (SSLBs) have the potential to overcome this limitation and at the same time also increase the safety of the battery. ${ }^{1-4}$ Garnet-type $\mathrm{Li}_{7} \mathrm{La}_{3} \mathrm{Zr}_{2} \mathrm{O}_{12}$ (LLZO) solid-state electrolyte has been drawing increasing attention since it was first synthesized by Murugan et al. in 2007, ${ }^{5}$ due to its high ionic conductivity (around $10^{-3}$ $\mathrm{S} \mathrm{cm}^{-1}$ at room temperature (RT) in sintered pellets), ${ }^{6-8}$ wide electrochemical stability window (being stable against metallic lithium and up to $\left.6 \mathrm{~V} \mathrm{vs} \mathrm{Li}^{+}\right),{ }^{5,9-11}$ and robust mechanical and thermal stabilities. ${ }^{12,13}$ Superior Li-ion conductivities are only observed in the high-temperature cubic phase of the garnet. ${ }^{14-16}$ Nevertheless, stabilization of the high-temperature cubic phase at room temperature can be achieved by partially substituting the element sitting on one of the crystal lattice sites by an aliovalent element. The most common and successful approach consists of partially replacing the Li $24 d$ sites by a trivalent metallic cation such as $\mathrm{Al}^{3+}, \mathrm{Ga}^{3+}$, or $\mathrm{Fe}^{3+}$, which increases the number of $\mathrm{Li}^{+}$vacancies. $15,17-20$
Sub-micron-thick LLZO can be deposited using common thin film processing techniques (such as plasma sputtering, ${ }^{21}$ pulsed laser deposition, ${ }^{22}$ chemical vapor deposition, ${ }^{23}$ solgel $^{24}$ atomic layer deposition, ${ }^{25}$ etc.). This fabrication approach could enable LLZO solid-state batteries with higher energy density at lower fabrication costs, in comparison to the fabrication approaches based on high-temperature sintering of ceramic pellets typically employed by the research community nowadays. Thin film electrolytes can significantly decrease the amount of nonactive material in a battery, thus reducing the stack size and increasing the energy density. Thin film processing can also enable new applications such as the fabrication of on-chip batteries or the development of flexible batteries.

However, the current best ionic conductivities measured in LLZO thin films $(<1 \mu \mathrm{m})$, even with the addition of stabilizer elements, lag behind by about 2 orders of magnitude in comparison to that of the bulk material. Reported values for

Received: July 24, 2019

Accepted: November 12, 2019

Published: November 12, 2019 
Step 1: Cosputtering Deposition

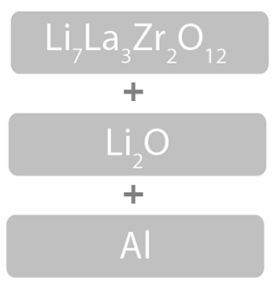

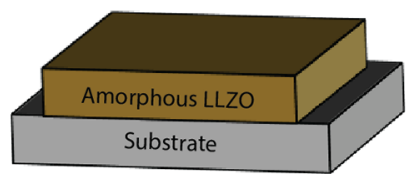

Step 2: Postannealing

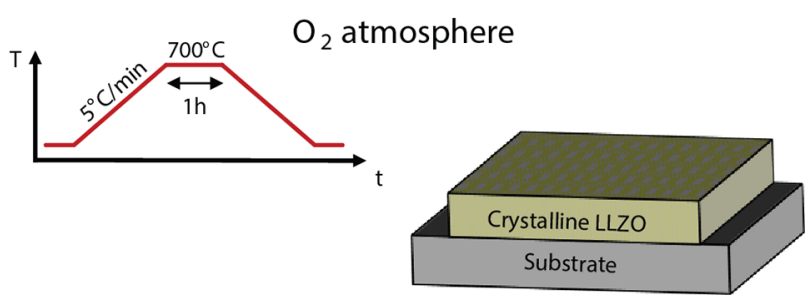

Figure 1. Schematic of the sample preparation process. Amorphous LLZO thin films are deposited by sputtering $\mathrm{Li}_{7} \mathrm{La}_{3} \mathrm{Zr}_{2} \mathrm{O}_{12}, \mathrm{Li}_{2} \mathrm{O}$, and $\mathrm{Al}$ targets. Sputtered films are postannealed in a $\mathrm{O}_{2}$ atmosphere at $700{ }^{\circ} \mathrm{C}$ for $1 \mathrm{~h}$ in order to crystallize the LLZO.

LLZO thin films range from $10^{-10}$ up to $10^{-5} \mathrm{~S}$ $\mathrm{cm}^{-1} \cdot{ }^{21,23,24,26-31}$ The work of Lobe et al. ${ }^{32}$ shows an ionic conductivity in sputtered LLZO thin films comparable to the ones obtained with pellet samples; however, the in-plane conductivity measurements in that work were conducted using a conductive substrate, which might lead to an erroneous measurement of the ionic conductivity in the electrolyte. Very recently, Pfenninger et al. ${ }^{33}$ reported a record value of $2.9 \times$ $10^{-5} \mathrm{~S} \mathrm{~cm}^{-1}$ measured in-plane on a $\mathrm{MgO}$ substrate. In this work the films were fabricated using a pulsed laser deposition technique followed by a postannealing step at about $700{ }^{\circ} \mathrm{C}$. The as-deposited films were overlithiated by introducing thin interlayers of $\mathrm{Li}_{3} \mathrm{~N}$.

The inferior ionic conductivity observed in LLZO thin films as compared to pellets and sheets may be related to the limited annealing temperature that is required to avoid a massive $\mathrm{Li}$ loss and the formation of nonconductive phases. Due to the high surface to volume ratio, $\mathrm{Li}$ evaporates more easily in a thin film. Thus, crystallization and densification are not easy to achieve with thin film processing methods, unlike in bulk pellets. Improving the ionic conductivity and achieving dense thin films under a relatively low annealing temperature are still challenges for this type of thin film electrolyte.

In this work we investigate the effects of excess lithium and incorporation of aluminum on the crystalline phase, density, and air stability of LLZO thin films, and how these two parameters can ultimately improve the ionic conductivity of LLZO thin films. For this study LLZO films were prepared using a cosputtering process followed by postannealing in oxygen atmosphere at $700{ }^{\circ} \mathrm{C}$, about $400{ }^{\circ} \mathrm{C}$ below the typical temperatures employed in pellet processing. Our study reveals that stabilizing the cubic phase of LLZO is not the only key factor for obtaining a highly conductive LLZO thin film, but as expected, a dense and homogeneous microstructure is also very important. High porosity limits the ionic conductivity and is detrimental for the phase stability. In this sense, we studied the effect of air-induced degradation in films prepared with different amounts of $\mathrm{Li}$ and with $\mathrm{Al}$.

The ionic conductivity of $1.9 \times 10^{-5} \mathrm{~S} \mathrm{~cm}^{-1}$ obtained with Al-substituted LLZO thin films represents the highest value for sputtered LLZO thin films ${ }^{21}$ and is in the same order of the value reported by Pfenninger et al. using pulsed laser deposition. ${ }^{33}$ This value still lags about 1 order of magnitude behind the average LLZO pellet. However, taking into consideration the thickness of the film $(400 \mathrm{~nm})$, the crossplane ionic resistance of this film is only $2.06 \Omega \mathrm{cm}^{2}$, about 50 times lower than the typical $1 \mathrm{~mm}$ thick pellet with a conductivity of $1 \mathrm{mS} \mathrm{cm}{ }^{-1}$. This quantity provides evidence of the advantage of LLZO thin films in comparison to pellets: high ionic conductances can be achieved with lower processing temperatures and lower weight of the electrolyte.

\section{METHODS}

2.1. Thin Film Deposition. LLZO thin films of $400 \mathrm{~nm}$ were prepared on $10 \times 10 \mathrm{~mm}^{2}$ polished $\mathrm{MgO}(100)$ single-crystal substrates (Jiangyin Maideli Advanced Materials Co., Ltd.). Films were prepared on $\mathrm{MgO}$ single-crystal substrates, which have a very low reactivity and diffusivity, to avoid possible reactions of the substrate with the film and the formation of secondary phases. This is a commonly used substrate in the investigation of LLZO thin films. ${ }^{21,22,33-35}$ The deposition was carried out at room temperature by a radio frequency (RF) magnetron sputtering system (Orion, AJA International Inc.) with a confocal off-axis target configuration. $\mathrm{Li}_{7} \mathrm{La}_{3} \mathrm{Zr}_{2} \mathrm{O}_{12}$ (3N, $90 \%$ density) and $\mathrm{Li}_{2} \mathrm{O}$ (3N, $90 \%$ density) targets from Toshima Manufacturing Co. were cosputtered in order to deposit LLZO films with an excess of lithium. The sputtering process was performed at $0.3 \mathrm{~Pa}$ using a $50 \mathrm{sccm} \mathrm{Ar}+1 \mathrm{sccm} \mathrm{Ar}: \mathrm{O}_{2}$ gas flow. The deposition rate of each target was controlled independently via the sputtering power and monitored using a quartz crystal microbalance (QCM) sensor. Samples were prepared with an excess lithium ranging from 9.0(5) to 19.0(5) extra moles of Li per mole of LLZO.

$\mathrm{Li}_{7-3 x} \mathrm{Al}_{x} \mathrm{La}_{3} \mathrm{Zr}_{2} \mathrm{O}_{12} \quad$ (Al:LLZO) thin films were obtained by following a multilayer sputtering approach, consisting of a sequence of Li-rich LLZO (cosputtered $\mathrm{Li}_{7} \mathrm{La}_{3} \mathrm{Zr}_{2} \mathrm{O}_{12}$ and $\mathrm{Li}_{2} \mathrm{O}$ ) and aluminum metal layers. This approach was followed due to a high sputtering rate of $\mathrm{Al}$, which makes it infeasible to achieve a simultaneous cosputtering together with the LLZO. The sputtering of the Al target was performed with a $25 \mathrm{sccm}$ Ar flow at a pressure of $0.2 \mathrm{~Pa}$.

After deposition, the amorphous LLZO films were transferred to a tube furnace (Carbolite GHA 12/300) connected to a vacuum pump on one side and a mass flow controller (MFC) on the other. The samples were annealed at $700{ }^{\circ} \mathrm{C}$ for $1 \mathrm{~h}$ with a heating/cooling ramp of $5{ }^{\circ} \mathrm{C} / \mathrm{min}$. During the annealing, an $\mathrm{O}_{2}$ flow was passed through the tube and the pressure inside the tube was monitored and regulated using the MFC and vacuum pump.

Figure 1 shows a schematic of the deposition process and the postannealing step.

2.2. Characterization. The crystalline phase of the annealed LLZO thin films was assessed using in-plane grazing-incidence X-ray diffractometry (GI-XRD), impinging the sample with $\mathrm{Cu} K \alpha 1$ radiation at an incident angle $(\omega)$ of $2^{\circ}$ and measuring the diffracted radiation $(2 \theta)$ between $10^{\circ}$ and $80^{\circ}$. The samples annealed in the tube furnace were measured ex situ with a Bruker D8 Discover diffractometer. For the in situ XRD measurements, a PANalytical $\mathrm{X}^{\prime}$ Pert $^{3}$ diffractometer was employed instead. In this case, XRD patterns were captured at different temperature stages during the annealing process. Phase identification and Rietveld refinements of the lattice constants were performed using the open-source software Profex.

The microstructure of the films was studied from cross-section and top-view images acquired with a scanning electron microscope (SEM) (Hitachi FEG-SEM S-4800). Cross-section samples were prepared by 

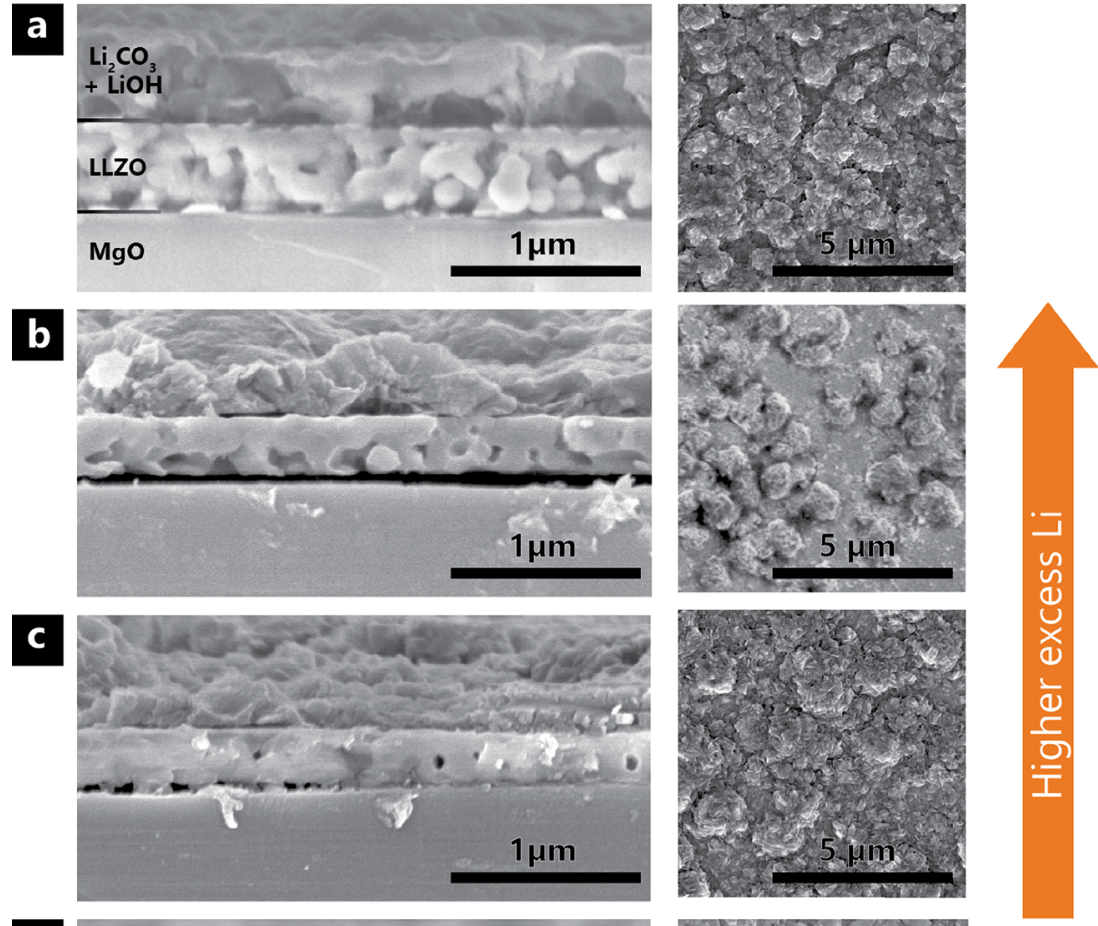

d
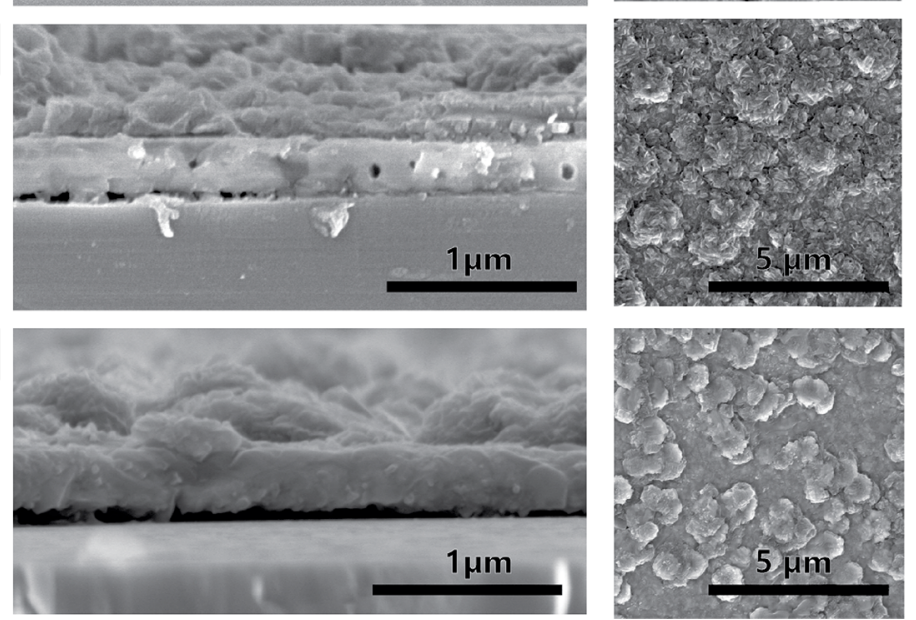

Figure 2. Cross-section and top-view SEM micrographs of annealed LLZO thin films on MgO prepared with different amounts of excess Li: (a) 19.0(5), (b) 14.0(5), (c) 13.0(5), and (d) 11.0(5) extra moles of Li per mole of LLZO.

cleaving the $\mathrm{MgO}$ substrate using a diamond scriber and cleaving pliers.

The lithium-ion conductivity and its activation energy were extracted from temperature-dependent impedance spectroscopy. For this measurement, $\mathrm{Au}$ contacts with a thickness of $\sim 70 \mathrm{~nm}$ and a parallel spacing of $200 \mu \mathrm{m}$ were thermally evaporated on the films after the postannealing step. Given the large ratio between the electrode separation and film thickness $(t / w \sim 500)$, we can neglect any fringe conductance. The impedance of the LLZO films was measured from $1 \mathrm{~Hz}$ to $10 \mathrm{MHz}$ with an amplitude of $50 \mathrm{mV}$ using a Paios all-in-one characterization system (Fluxim AG). The temperature of the sample was regulated using a temperature-controlled stage (Linkam LTSE-420-P) integrated with the measurement system. A PT100 temperature sensor was contacted on the sample's surface to $\log$ its actual temperature. Impedance spectra were acquired for set temperatures ranging from $298 \mathrm{~K}$ up to $600 \mathrm{~K}$. The measurement chamber was flooded with Ar to prevent degradation of the LLZO films.

The measured data was fitted using an equivalent circuit consisting of a series resistance $\left(R_{\mathrm{s}}\right)$ connected in series to a capacitance $\left(C_{\text {geom }}\right)$ in parallel with a resistance $\left(R_{\text {ion }}\right)$ and a constant phase element $\left(\mathrm{CPE}_{\text {int }}\right)$, as proposed by Huggins et al. ${ }^{36} R_{\mathrm{s}}$ represents the series resistance introduced by the contacts, $C_{\text {geom }}$ the capacitance due to the geometry of the electrodes, $R_{\text {ion }}$ the ionic resistance of the electrolyte, and $\mathrm{CPE}_{\text {int }}$ a constant phase element modeling the doublelayer interface between the electrolyte and the electrodes. The resistance $R_{\text {ion }}$ is a combination of the bulk and grain boundary ionic resistances, from which the effective ionic conductivity $\left(\sigma_{\text {ion,eff }}\right)$ can be calculated from eq 1

$$
\sigma_{\text {ion,eff }}=\frac{l}{R_{\text {ion }} w t}
$$

where $l$ is the electrode separation, $w$ the electrode width, and $t$ the film thickness. More details on this calculation are provided in the Supporting Information.

The effective ionic conductivities $\sigma_{\text {ion,eff }}$ at different temperatures were fitted to the Arrhenius equation:

$$
\sigma_{\text {ion,eff }} T=A e^{-E_{\mathrm{a}} / k_{\mathrm{B}} T}
$$

where $A$ is the frequency prefactor, $T$ is the temperature measured on the film, $E_{\mathrm{a}}$ is the activation energy of the ion transport mechanism, and $k_{\mathrm{B}}$ is Boltzmann's constant.

Standard time-of-flight secondary ion mass spectrometry (ToFSIMS) profiles were measured in a ToF.SIMS ${ }^{5}$ unit from IONTOF. Depth profiling was performed by $\mathrm{Cs}^{+}$-ion sputtering with an acceleration voltage of $2 \mathrm{kV}$ on an area of $300 \times 300 \mu \mathrm{m}^{2}$. The primary ion source used for imaging was $\mathrm{Bi}^{+}$with an acceleration voltage of $25 \mathrm{kV}$ and a current of approximately $0.6 \mathrm{pA}$. Measurements were performed on a $100 \times 100 \mu \mathrm{m}^{2}$ area within the sputtering crater. A floodgun was used to avoid surface charging.

A 3D elemental distribution of the thin film was obtained using a high-resolution time-of-flight (HTOF) mass spectrometer from TOFWERK which was incorporated into a focused ion beam/ scanning electron microscope (FIB/SEM) LYRA3 from Tescan. Measurements were conducted in a positive ion detection mode using a $180 \mathrm{pA}$ continuous polyisotopic $\mathrm{Ga}^{+}$beam with an energy of $20 \mathrm{keV}$ $(100 \mu \mathrm{m}$ aperture, $32 \mu \mathrm{s}$ dwell time, $512 \times 512$ resolution, and $2 \times 2$ binning). The pressure in the analytical chamber was in the range (69) $\times 10^{-6}$ mbar. The FIB scanning area was set to $10 \times 10 \mu \mathrm{m}^{2}$, but 
As-deposited

b After annealing

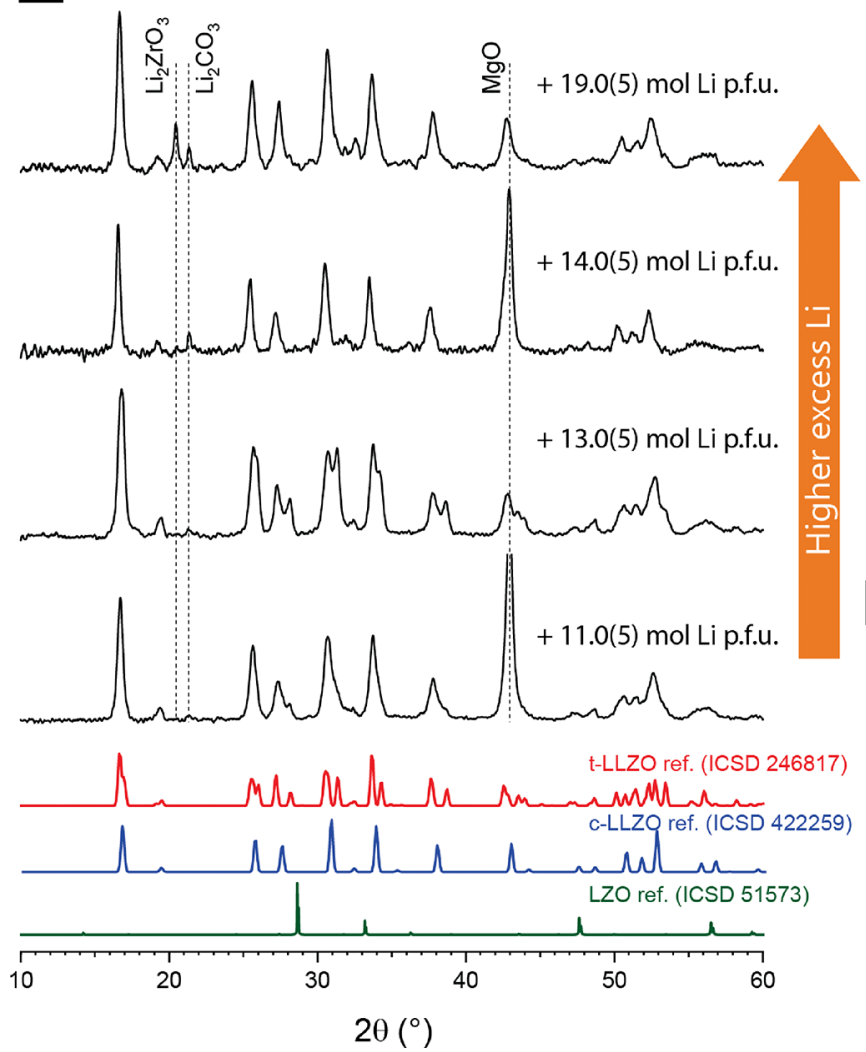

c

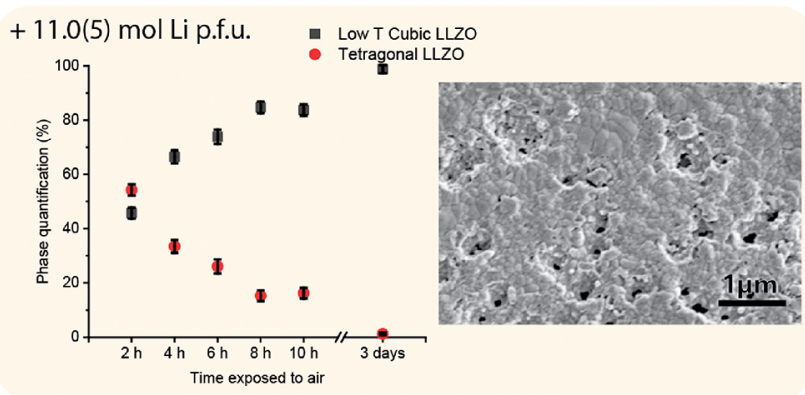

$+9.0(5)$ mol Li p.f.u. $\quad$ Low T Cubic LLzo

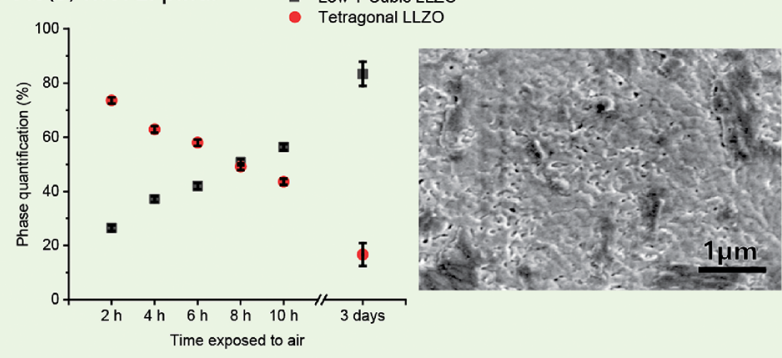

d
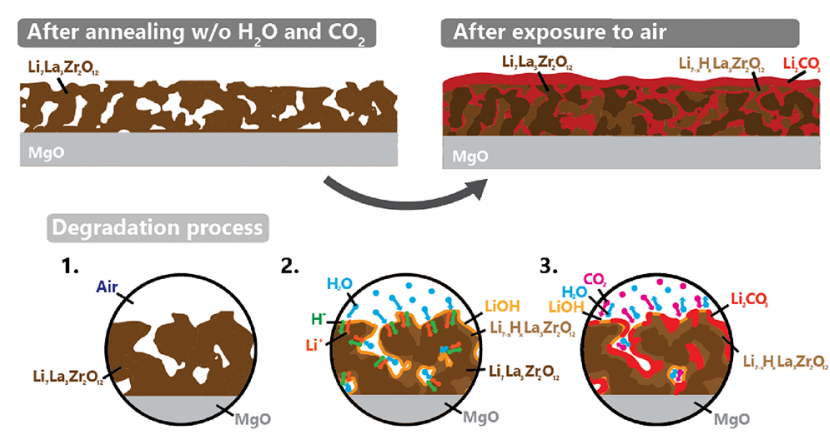

Figure 3. Grazing-incidence X-ray diffraction patterns of (a) an as-deposited LLZO film and (b) postannealed films with different amounts of excess Li: 19.0(5), 14.0(5), 13.0(5), and 11.0(5) extra moles of $\mathrm{Li}$ per mole of LLZO (from top to bottom). (c) Phase ratio (tetragonal vs $\mathrm{H}^{+}$stabilized cubic LLZO) evolution of LLZO films exposed to air at room temperature, and the top-view SEM micrographs of the film's surfaces. Samples prepared with 9.0(5) and 11.0(5) moles of extra Li per mole of LLZO. (d) Schematic of the degradation process of porous pristine LLZO thin films when exposed to air.

only a central $5 \times 5 \mu \mathrm{m}^{2}$ region was taken into account to prevent possible crater edge-induced artifacts. The collected 4D $(x, y, z$ and corresponding mass spectra) data set was mass-calibrated using the TOF-SIMS signals of the main sample component, i.e., ${ }^{7} \mathrm{Li}$ and both isotopes of the FIB beam $\left({ }^{69} \mathrm{Ga}\right.$ and $\left.{ }^{71} \mathrm{Ga}\right)$. The total signal was then decomposed in order to assess the information on single element distributions in $3 \mathrm{D}$.

\section{RESULTS AND DISCUSSION}

3.1. Effects of Li Excess. 3.1.1. Film Morphology. As previously shown by Rawlence et al., ${ }^{21}$ sputtered thin films of LLZO crystallize in the nonconductive pyrochlore-type $\mathrm{La}_{2} \mathrm{Zr}_{2} \mathrm{O}_{7}$ phase when no additional $\mathrm{Li}$ is added to the film during preparation. This is a consequence of the loss of Li that occurs during the sputtering and especially during the postannealing process. Cosputtering of $\mathrm{Li}_{2} \mathrm{O}$ is an effective approach to overlithiate the as-deposited films and achieve a crystalline LLZO phase after postannealing. Rawlence et al. ${ }^{21}$ reported that an excess of $\mathrm{Li}$ above $8 \mathrm{~mol}\left(4 \mathrm{~mol}\right.$ of $\left.\mathrm{Li}_{2} \mathrm{O}\right)$ per formula unit (p.f.u.) of LLZO was necessary to prevent the formation of nonconductive phases in LLZO thin films annealed at $700{ }^{\circ} \mathrm{C}$ for $1 \mathrm{~h}$ (similar conditions to the ones employed in this work). In the first part of this work we investigate the effect of further increasing the amount of $\mathrm{Li}$ in the as-deposited LLZO films, based on the hypothesis that an increase in lithium amount p.f.u. would have an effect on the microstructure of the films and their ionic conductivity. To decouple the effect of excess lithium from the effect of a substitutional element in the film microstructure, pristine LLZO thin films (without any substitutional element) were first investigated.

A series of pristine LLZO samples were prepared with different ratios of $\mathrm{LLZO}$ and $\mathrm{Li}_{2} \mathrm{O}$ deposition rates to control the excess amount of $\mathrm{Li}$ in the film. In addition, an interlayer of $\sim 15 \mathrm{~nm} \mathrm{Li} 2 \mathrm{O}$ was in some cases added between the $\mathrm{MgO}$ substrate and the LLZO film to further increase the level of lithiation. The amount of $\mathrm{Li}$ in the as-deposited film was calculated on the basis of the deposition rates measured with a quartz crystal microbalance (QCM) during the sputtering process. This method is not as accurate as other analysis techniques, but it offers a simple, fast, and nondestructive way to estimate the amount of $\mathrm{Li}$ in the as-prepared films. Given the lower accuracy of the method, wide error margins $( \pm 0.5$ mol p.f.u.) are provided in the reported values. This margin of error was assessed on the basis of ICP-MS quantifications, which provide a higher level of accuracy. 
Figure 2 shows cross-sectional and top-view SEM micrographs of LLZO thin films with different amounts of excess Li: 11.0(5), 13.0(5), 14.0(5), and 19.0(5) moles of excess Li p.f.u. of LLZO. The gaps between the substrate and the film observable in the cross-section SEM images appear due to the preparation of the samples. The $\mathrm{MgO}$ is cleaved, and therefore, the films become slightly detached due to the mechanical stress (FIB cross sections like the one in Figure S6 do not show such delamination). In all cases a layer of $\mathrm{Li}_{2} \mathrm{CO}_{3}$ and $\mathrm{LiOH}$ covers the LLZO film, which results from the exposure to air of the samples (while preparing the samples for SEM imaging) and the reaction of $\mathrm{Li}^{+}$with moisture and $\mathrm{CO}_{2}$. In this series of samples, an increasing excess of $\mathrm{Li}$ has a detrimental effect on the LLZO film density. The higher the amount of excess $\mathrm{Li}$ is, the higher the porosity of the film. We suggest that these microstructural features appear due to the excess lithium segregating at the grain surfaces during annealing and promoting the formation of pores as a result of the vaporization of lithium oxide. In Figure $S 1$ one can observe that the as-deposited film is dense, but it becomes porous after the annealing step. This phenomenon is in good agreement with the first-principles density functional theory study conducted by Canepa et al., ${ }^{37}$ which predicts a spontaneous segregation of $\mathrm{Li}$ toward the particle boundaries during sintering. The high volatility of $\mathrm{Li}_{2} \mathrm{O}$ at the temperature range at which the samples were processed leads to the vaporization of the segregated lithium in the form of gaseous lithium $\left(\mathrm{Li}_{2} \mathrm{O}(\mathrm{s}) \rightarrow 2 \mathrm{Li}(\mathrm{g})+\frac{1}{2} \mathrm{O}_{2}(\mathrm{~g})\right)$ and gaseous lithium oxide $\left(\mathrm{Li}_{2} \mathrm{O}(\mathrm{s}) \rightarrow \mathrm{Li}_{2} \mathrm{O}(\mathrm{g})\right)$. $^{38,39}$

3.1.2. Crystalline Phase. The X-ray diffraction (XRD) pattern of the as-deposited films shows a completely amorphous phase, as seen in Figure 3a. After the postannealing step all the prepared samples present a crystalline LLZO phase, as seen in the XRD patterns shown in Figure $3 \mathrm{~b}$. Rietveld refinements of the XRD measurements using as a reference the tetragonal LLZO phase (ICSD 246817) yield lattice constants of $a=13.1(1) \AA$ and $c=12.7(1) \AA$ for all four cases, in good agreement with previously reported values for tetragonal LLZO. The nonconductive $\mathrm{La}_{2} \mathrm{Zr}_{2} \mathrm{O}_{7}$ phase does not appear in any of the shown samples, which indicates that in all cases there is enough $\mathrm{Li}$ in the as-deposited film. One can observe that a peak corresponding to $\mathrm{Li}_{2} \mathrm{CO}_{3}$ appears around $2 \theta=22^{\circ}$. This peak is more intense in the films with higher excess $\mathrm{Li}$, but the intensity considerably drops in the films with less $\mathrm{Li}$, indicating that the samples prepared with higher excess $\mathrm{Li}$ are more prone to form $\mathrm{Li}_{2} \mathrm{CO}_{3}$ when exposed to air. This difference in the amount of $\mathrm{Li}_{2} \mathrm{CO}_{3}$ can also be observed in the SEM images on Figure 2. At $2 \theta=20^{\circ}$ an additional peak can also be observed in the XRD patterns of the films with a higher excess of $\mathrm{Li}$. This peak can be identified as $\mathrm{Li}_{2} \mathrm{ZrO}_{3}$, that also results from the excess $\mathrm{Li}$.

In order to assess the Li loss during the processing steps, the $\mathrm{Li}$ amount in a postannealed thin film was quantified using ICP-MS. The amount of $\mathrm{Li}$ in the film, prepared with 16.0(5) moles of $\mathrm{Li}$ p.f.u. ( 9 extra moles of $\mathrm{Li}$ p.f.u., based on the deposition rates), was measured to be $8.92 \mathrm{~mol}$ p.f.u. (see Table S1), meaning that approximately 7 moles of Li p.f.u. are lost during the processing step for this given excess lithium. This can be used to draw a boundary at around 7 moles of excess lithium required to obtain a fully LLZO phase. With an initial $\mathrm{Li}$ amount below $14 \mathrm{~mol}$ p.f.u., the resulting composition after annealing would lay under the 7 moles of $\mathrm{Li}$ p.f.u. required for stoichiometric balance, and therefore would result in the formation of $\mathrm{La}_{2} \mathrm{Zr}_{2} \mathrm{O}_{7}$.

The amount of Li loss is strongly related to the annealing conditions (atmosphere, pressure, temperature, dwelling, etc.). For example, reducing the annealing pressure increases substantially the Li loss. In Figure S2 we show the resulting phases from two samples with a high excess of $\mathrm{Li}(19.0$ (5) mol p.f.u.) annealed, respectively, at a pressure of $1 \mathrm{mbar}$ and 200 mbar in a pure $\mathrm{O}_{2}$ atmosphere. The LLZO film crystallized at lower pressure shows a predominant Li-deficient $\mathrm{La}_{2} \mathrm{Zr}_{2} \mathrm{O}_{7}$ phase, whereas in the sample annealed at higher partial pressure of $\mathrm{O}_{2}$, a pure LLZO phase is formed, with residual $\mathrm{Li}_{2} \mathrm{CO}_{3}$ and $\mathrm{Li}_{2} \mathrm{ZrO}_{3}$ due to an excess of $\mathrm{Li}$.

These results point out the necessity of precisely controlling the amount of excess $\mathrm{Li}$ in the sputtered LLZO films if one seeks to fabricate compact and homogeneous films with high ionic conductivity. On one side, a deficit of $\mathrm{Li}$ will prevent the formation of the LLZO crystalline phase, leading to the formation of non-ionic-conductive phases, which are ineffective as an electrolyte. On the other side, excessive $\mathrm{Li}$ will result in less compact films, with pores and pinholes that would be very detrimental for the operation of an LLZO-based SSLB, as dendrites and shunts across electrodes could easily form.

Despite the lack of phase stabilizer, we observe that the samples prepared with different amounts of excess $\mathrm{Li}$ do not only show a fully tetragonal LLZO phase. As one can observe in Figure $3 \mathrm{~b}$, some samples show a more prominent peak splitting, characteristic of the tetragonal polymorph, whereas others show only single peaks, characteristic of the cubic polymorph. However, in all cases, phase quantification using Rietveld refinements yielded as a result a mixture of both phases, in different proportions depending on the as-deposited composition and handling history. Since the annealing process was performed in a sealed tube furnace without significant amount of air leaking in, it can be ruled out that this lowtemperature cubic phase was occurring during the annealing, as is the case in the work of Xie et al. ${ }^{40}$ and Quinzeni et al. ${ }^{41}$ Indeed, Rawlence et al. $^{21}$ reported that nonstabilized LLZO thin films annealed in oxygen have a fully tetragonal phase prior to air exposure (as observed in the in situ XRD measurements).

We observe that samples prepared in the same batch had significantly different ratios between the cubic and tetragonal phases depending on the presence or absence of gold contacts (deposited after processing for the ionic conductivity measurements). The samples covered with gold tend to have a prominent tetragonal phase, as a result of the sealing effect provided by the gold, whereas samples without mostly show the cubic phase. Moreover, the ratio of tetragonal and cubic phases also depends on the sample history and especially on the length of time the samples have been exposed to air.

We performed systematic studies of this phase evolution using time-sequential XRD scans. Two freshly annealed samples with different amounts of excess $\mathrm{Li}$ in the as-deposited film (9.0(5) and 11.0(5) moles of excess Li p.f.u, respectively) were sequentially measured over the span of $10 \mathrm{~h}$ and after 3 days in air. Figure S3 shows the XRD patterns of the films after different air exposure periods. The phases were quantified using Rietveld refinements. Figure $3 \mathrm{c}$ shows the change in phase percentages obtained from the phase quantification. The cubic phase that appears in both films when exposed to air has a lattice constant above $13.0 \AA$, larger than the reported value of the high-temperature cubic phase. The value we obtain here 
a
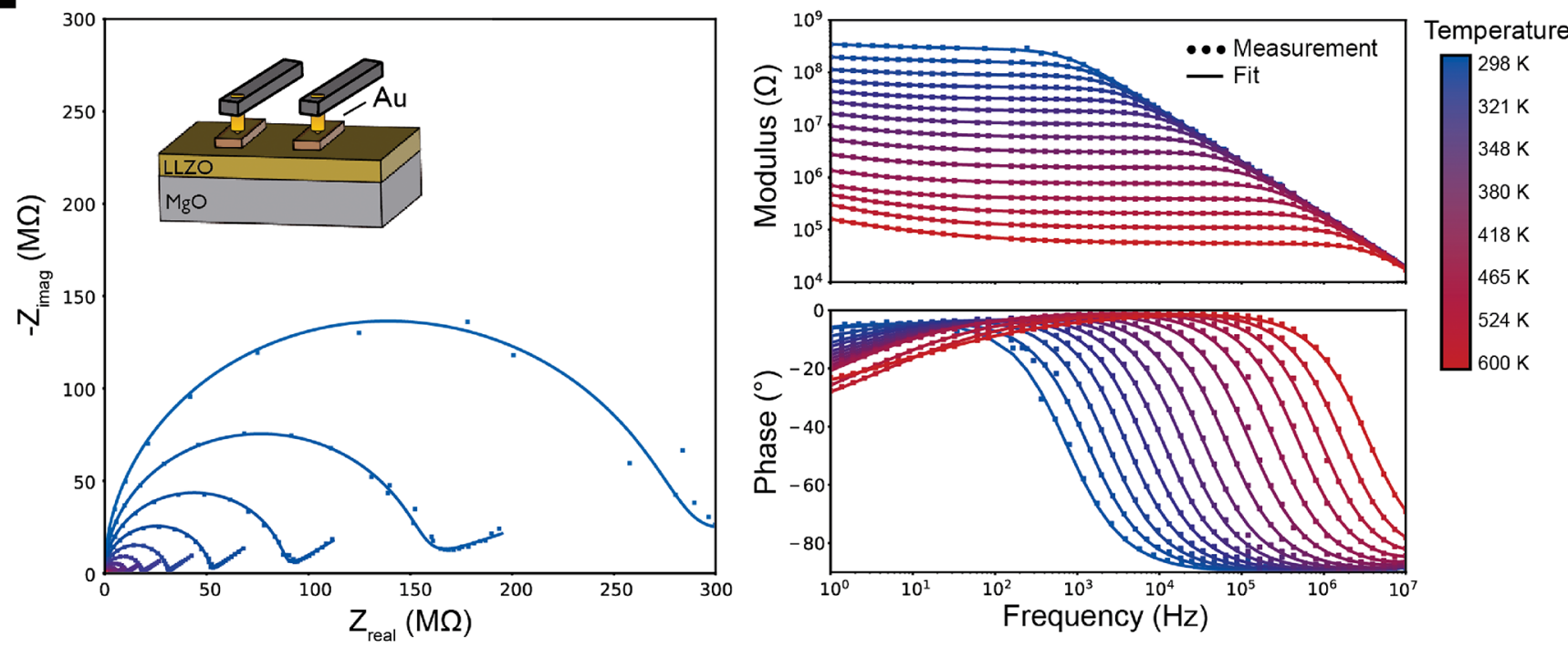

b

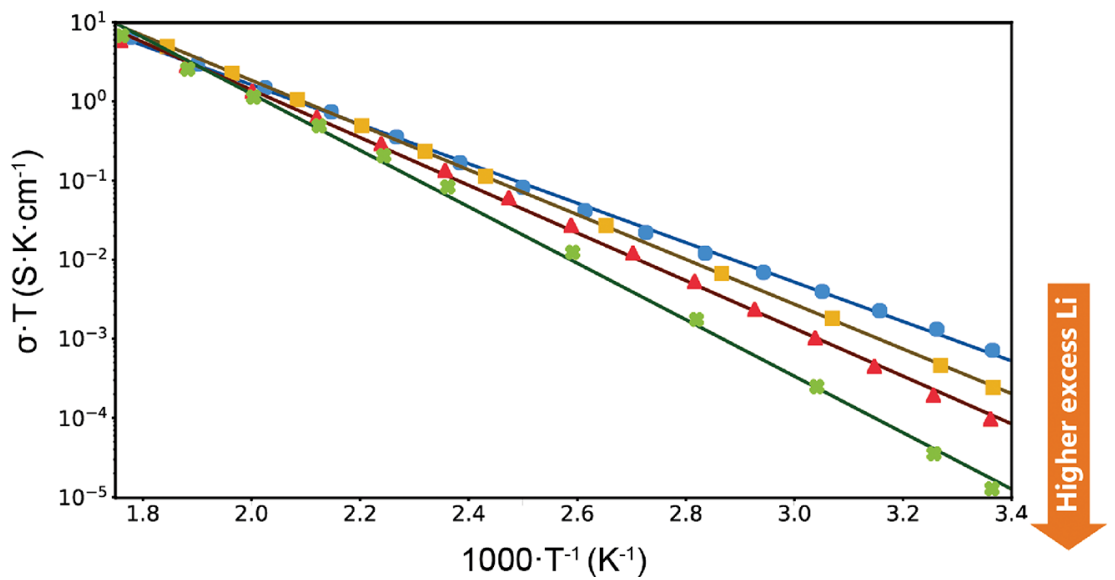

$-++9.0(5)$ mols Li p.f.u. $\mathrm{E}_{\mathrm{a}}=0.494(4) \mathrm{eV}$

$\sigma_{\mathrm{RT}}=2.47(10) \cdot 10^{-6} \mathrm{~S} / \mathrm{cm}$

- + + 10.0(5) mols Li p.f.u.

$\mathrm{E}_{\mathrm{a}}=0.562(1) \mathrm{eV}$

$\sigma_{\mathrm{RT}}=8.30(38) \cdot 10^{-7} \mathrm{~S} / \mathrm{cm}$

$\neg++11.0(5)$ mols Li p.f.u.

$\mathrm{E}_{\mathrm{a}}=0.598(6) \mathrm{eV}$

$\sigma_{\mathrm{RT}}=3.32(12) \cdot 10^{-7} \mathrm{~S} / \mathrm{cm}$

$-\infty-+12.0(5)$ mols Li p.f.u.

$\mathrm{E}_{\mathrm{a}}=0.708(11) \mathrm{eV}$

$\sigma_{\mathrm{RT}}=4.39(119) \cdot 10^{-8} \mathrm{~S} / \mathrm{cm}$

Figure 4. (a) Nyquist plot and Bode plot of the impedance spectroscopy data measured and the fitted data at temperatures ranging from 298 to $600 \mathrm{~K}$ on the sample with 9.0(5) excess moles of Li p.f.u. Inserts show the measurement setup. (b) Arrhenius plots of the effective ionic conductivity of four samples prepared with different amounts of excess Li.

agrees well with the reported lattice constants of the lowtemperature cubic phase of LLZO. ${ }^{42-44}$ With this observation we conclude that the LLZO films undergo a phase transformation (from tetragonal to cubic) at room temperature in the presence of $\mathrm{H}_{2} \mathrm{O}$ and $\mathrm{CO}_{2}$.

In both cases a clear evolution from an initially predominant tetragonal phase to a mostly cubic phase is observed after the film has been exposed to air for 3 days at RT. However, the speed of this transition is significantly different: the first sample rapidly becomes cubic whereas the second one takes several hours to become predominantly cubic. As seen in the top-view SEM images of the samples after removing residues from the surface using methanol (Figure 3c), the sample with a higher amount of excess Li presents a significantly higher number of pores as well as some pinholes, which entails a higher airexposed surface with respect to the total volume.

As reported by Sharafi et al., ${ }^{45}$ when LLZO pellets are exposed to air, they undergo a spontaneous reaction with moisture resulting in a $\mathrm{Li}^{+} / \mathrm{H}^{+}$exchange and the formation of lithium hydroxide on the surfaces:

$$
\mathrm{Li}_{7} \mathrm{La}_{3} \mathrm{Zr}_{2} \mathrm{O}_{12}+x \mathrm{H}_{2} \mathrm{O} \rightarrow \mathrm{Li}_{7-x} \mathrm{H}_{x} \mathrm{La}_{3} \mathrm{Zr}_{2} \mathrm{O}_{12}+x \mathrm{LiOH}
$$

Subsequently, the $\mathrm{LiOH}$ present on the surface further reacts with $\mathrm{CO}_{2}$ to yield $\mathrm{Li}_{2} \mathrm{CO}_{3}$ :

$$
2 \mathrm{LiOH}+\mathrm{CO}_{2} \rightarrow \mathrm{Li}_{2} \mathrm{CO}_{3}+\mathrm{H}_{2} \mathrm{O}
$$

The cross-sectional and top-view SEM images shown in Figure 2 provide evidence of the formation of a residual layer on top of the LLZO thin films after exposure to air. The thickness of this layer is dependent on the amount of excess $\mathrm{Li}$ in the as-deposited film. This agrees with the proposed degradation mechanism: the higher the concentration of $\mathrm{Li}$ is, the more porous the film becomes during annealing and the larger the amount of $\mathrm{Li}_{2} \mathrm{CO}_{3}$ formed on the surface when exposed to air, due to the higher surface to volume ratio.

Figure $3 \mathrm{~d}$ depicts the degradation mechanism of LLZO thin films in air. A higher porosity of the film implies that larger surface area will be exposed to air and therefore the faster and more extensive the degradation process will be.

ToF-SIMS was performed in two degraded samples with different amounts of deposited excess Li. Figure S4 shows the depth profiles of the $\mathrm{Li}^{-}, \mathrm{C}^{-}, \mathrm{La}^{-}, \mathrm{Zr}^{-}$, and $\mathrm{MgO}^{-}$signals. These results confirm that a carbon-rich phase, namely, $\mathrm{Li}_{2} \mathrm{CO}_{3}$, is present on the upper surface of the LLZO films 
exposed to air. The sample with a higher amount of excess $\mathrm{Li}$ shows an apparently broader and less sharp interface between the $\mathrm{Li}_{2} \mathrm{CO}_{3}$ and LLZO layers. This can be correlated to the thicker residual layer observed in the SEM images as well as the higher porosity of the film, which allows the growth of $\mathrm{Li}_{2} \mathrm{CO}_{3}$ inside the film.

Energy-dispersive X-ray (EDX) spectroscopy also confirms the presence of a carbon-rich layer on the surface of the LLZO films (see Figure S5), confirming the formation of $\mathrm{Li}_{2} \mathrm{CO}_{3}$ on the LLZO surface after exposing the films to air.

The protonation of LLZO during this degradation process is the cause for the transition from a tetragonal phase to an expanded cubic geometry observed when the samples are exposed to air. With higher porosity, the protonation of LLZO thin films takes place faster as the surface to volume ratio is larger. The results on Figure $3 \mathrm{c}$ prove that a more compact LLZO film is more stable against air-induced degradation.

Similar to the substitution of $\mathrm{Li}^{+}$sites by supervalent cations, it is still not well-understood how the presence of protons in the lattice stabilizes the cubic polymorph of LLZO. It seems though that the destabilization of the ordered $\mathrm{Li}^{+}$sites is the cause for the rearrangement of the LLZO lattice.

The ionic conductivity of the films with a $\mathrm{H}^{+}$-stabilized cubic phase is expected to be similar or lower than the tetragonal LLZO, because the occupation of $\mathrm{Li}^{+}$sites by $\mathrm{H}^{+}$will reduce the amount of charge carriers and block the transport pathways. Moreover, the formation of $\mathrm{Li}_{2} \mathrm{CO}_{3}$ on the surfaces and particle boundaries will further increase the interfacial resistance. $^{46}$

In the case of films, due to the large surface to volume ratio, the formation of $\mathrm{LiOH}$ and $\mathrm{Li}_{2} \mathrm{CO}_{3}$ on the surface of the thin films has a significantly higher impact than in the case of pellets, for which different approaches to remove this degraded interface exist (polishing, heat treatment, chemical etching). ${ }^{47}$ Therefore, finding approaches to mitigate the air-induced degradation are key to improve the effective ionic conductivity of the films.

3.1.3. Li-Ion Conductivity. To study the ionic conductivity of the pristine LLZO thin films and its relation to the excess $\mathrm{Li}$ and film morphology, we conducted temperature-dependent impedance spectroscopy measurements on a selection of the prepared samples, as depicted in the inset in Figure 4a. The Nyquist and Bode plots of the data measured on the LLZO sample with an excess Li of 9.0(5) moles p.f.u are plotted in Figure 4a. The fitting of the data using the equivalent circuit described in the Methods section is also shown.

One can observe a single semicircle due to the geometric capacitance and the ionic resistance followed by a lowfrequency tail, resulting from the polarization at the ionblocking electrodes. The presence of only one arch could misleadingly be interpreted as the lack of grain boundaries. However, the lack of a space charge between the grain interior and the grain boundary also results in a combined arch, as no capacitance appears at the boundary. The increase in the temperature results in a shrinking of the semicircles as a result of lower ionic resistances. The effect of the temperature can be better noticed in the Bode plot in Figure 4a. This behavior indicates a thermally activated ionic transport mechanism. The parameters resulting from the fitting can be found in Table S2.

The room temperature effective ionic conductivities of the pristine LLZO films with different amounts of excess $\mathrm{Li}$ in the as-deposited film can be found in Table 1. The error provided is based on the goodness of the fitting.
Table 1. Ionic Conductivity at Room Temperature and Activation Energy of Pristine LLZO Thin Films Prepared with Different Amounts of Excess Li p.f.u

\begin{tabular}{ccc}
$\begin{array}{c}\text { excess Li p.f.u. in the as- } \\
\text { deposited film }[\mathrm{mol}]\end{array}$ & $\begin{array}{c}\text { ionic conductivity at RT } \\
{\left[\mathrm{S} \mathrm{cm}^{-1}\right]}\end{array}$ & $\begin{array}{c}\text { activation } \\
\text { energy }[\mathrm{eV}]\end{array}$ \\
$9.0(5)$ & $2.47(10) \times 10^{-6}$ & $0.494(4)$ \\
$10.0(5)$ & $8.30(38) \times 10^{-7}$ & $0.562(1)$ \\
$11.0(5)$ & $3.32(12) \times 10^{-7}$ & $0.598(6)$ \\
$12.0(5)$ & $4.39(119) \times 10^{-8}$ & $0.708(11)$ \\
\hline
\end{tabular}

The measured ionic conductivities show a clear correlation with the amount of excess $\mathrm{Li}$ added during the sputtering of the films and hence with the morphology. The higher porosity produced by the excess Li results in a poorer conductivity of the films, as the tortuosity of the $\mathrm{Li}^{+}$migration pathways increases. The highest conductivity was measured in the samples with an excess of $\mathrm{Li}$ of 9.0(5) mol p.f.u., which is the densest film obtained without nonconductive phases (namely, $\mathrm{La}_{2} \mathrm{Zr}_{2} \mathrm{O}_{7}$ ). This value is very similar to the ionic conductivity reported for tetragonal LLZO thin films prepared with laserassisted CVD by Loho et $\mathrm{al}^{23}$ and is around 1 order of magnitude lower than the highest conductivity measured for tetragonal LLZO in a sintered pellet by Wolfenstine et al. ${ }^{16}$

The Arrhenius plots of the LLZO films with excess $\mathrm{Li}$ amounts ranging from $9.0(5)$ to $12.0(5) \mathrm{mol}$ p.f.u. are shown in Figure $4 \mathrm{~b}$. The activation energies range from $0.494(4) \mathrm{eV}$ (in the sample with $9.0(5)$ extra moles of $\mathrm{Li}$ ) to $0.708(11) \mathrm{eV}$ (in the sample with $12.0(5)$ extra moles of $\mathrm{Li}$ ). The best value, $0.494(4) \mathrm{eV}$, lies close to the $0.4 \mathrm{eV}$ theoretically predicted by Meier et al. ${ }^{48}$ for tetragonal LLZO.

The increase in the activation energy can be correlated with the density of the films as well. This finding is in agreement with the work by Wolfestine et al. ${ }^{16}$ They reported an activation energy of $0.41 \mathrm{eV}$ in a tetragonal LLZO pellet with a density close to the theoretical density. This value is considerably lower than in other experiments where lower density materials were studied. ${ }^{14,15,49}$ In the case of films with lower density, the contribution of the surface diffusion to the total conductivity will be more relevant. Assuming that the transport on the surface requires a higher activation energy, the effective activation energy of the films with a larger proportion of grain boundaries therefore will be higher.

3.2. Al:LLZO Thin Films. 3.2.1. Film Morphology. In the pristine LLZO, despite the improvements in the film homogeneity and compactness achieved with the regulation of the excess $\mathrm{Li}$, some porosity is still visible inside the film (see details in Figure 5a). By contrast, the Al-substituted LLZO film in Figure $5 b$, prepared with the same amount of excess $\mathrm{Li}$ p.f.u. (10(5) moles of excess $\mathrm{Li}$ p.f.u.), presents significantly larger grains that span across the film thickness and a more compact distribution. These observations provide evidence that a higher densification of the films is achieved through the incorporation of $\mathrm{Al}$.

Quantification of the porosity based on cross-sectional SEM images indicates a decrease in porosity of approximately $96 \%$ between the pristine LLZO film and the Al:LLZO sample annealed at higher pressure, as well as a significant reduction of the pores size (Feret diameter of porosity: $106.29 \mathrm{~nm}$ for the pristine LLZO and $33.52 \mathrm{~nm}$ for the Al:LLZO film).

We suggest that the $\mathrm{Al}$ incorporation plays a role as a sintering agent. The melting point of $\mathrm{Al}$ is around $660{ }^{\circ} \mathrm{C}$, which is below the annealing temperature of $700{ }^{\circ} \mathrm{C}$. The 
a

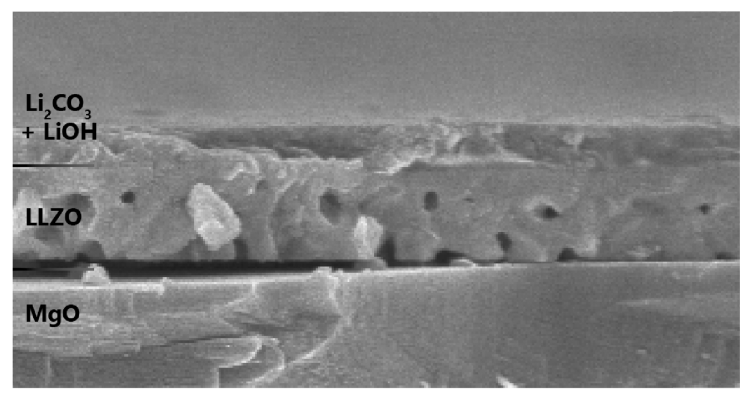

b

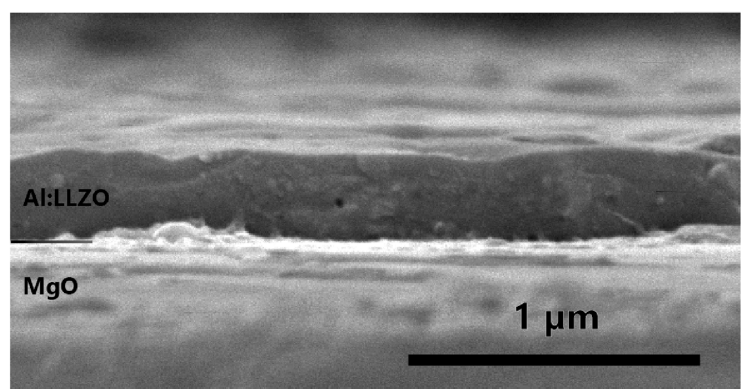

Figure 5. Cross-sectional SEM micrographs of (a) a pristine LLZO film and (b) an Al:LLZO film.

liquid phase of $\mathrm{Al}$ would change the edge retraction velocities from the surface diffusion; hence, it reduces the surface energy of LLZO as well as the solid-gas and solid-solid interfaces. $^{50-52}$ This role of aluminum as a sintering aid has been previously observed in the fabrication of LLZO pellets $^{51,53}$ and sheets, ${ }^{54}$ but it had not been reported in LLZO thin films annealed at lower temperature.

In order to further investigate the distribution of $\mathrm{Al}$ into the LLZO thin films, FIB-TOF-SIMS measurements were carried out. This technique allows the elemental structure of a sample to be represented in a three-dimensional space with a high mass resolution while still maintaining a high spatial resolution (the best lateral resolution of this system can reach about 50 $\mathrm{nm})$. See Supporting Information for more details on this technique and supporting figures (Figure S6). Figure 6a,b shows the TOF-SIMS signals of ${ }^{27} \mathrm{Al}$ and ${ }^{7} \mathrm{Li}$ on the analyzed area. Top views (Figure 6a) show images in the $x y$-plane integrated over 10 frames (i.e., FIB scans), and side views (Figure $6 \mathrm{~b}$ ) are the projections of the TOF-SIMS signals in the $x z$-plane integrated over $0.5 \mu \mathrm{m}$ in the $y$-direction. Figure $6 \mathrm{c}$ shows the FIB secondary electron (SE) images collected simultaneously during the sputtering process and the acquisition of secondary ions, which allow the sample topology to be monitored.

On the film's surface a stronger Li signal is observed, which spans over approximately $10 \mathrm{~nm}$. This can indicate that some residual $\mathrm{Li}_{2} \mathrm{O}$ is still present on the surface and has reacted with air forming $\mathrm{LiOH}$ and $\mathrm{Li}_{2} \mathrm{CO}_{3}$, resulting in a higher positive Li-ion yield than in the LLZO film. It must be noted however that, in comparison with the thickness of the $\mathrm{LiOH}+$ $\mathrm{Li}_{2} \mathrm{CO}_{3}$ forming on top of the pristine LLZO layers, the amount appearing on the Al:LLZO films is significantly lower. This observation is consistent with the cross-sectional SEM micrographs shown in Figures 2 and 5, in which a thick residual layer (about $100 \mathrm{~nm}$ ) is observed on top of the pristine films in comparison to the films with $\mathrm{Al}$.

The top (Figure 6a) and side (Figure $6 \mathrm{~b}$ ) views of the $\mathrm{Al}$ and $\mathrm{Li}$ signals provide evidence of a correlation between the spatial distribution of both elements. The two distributions follow similar patterns but are not exactly the same, which allows topology-induced artifacts to be excluded. This similarity can indicate a chemical interaction between $\mathrm{Li}$ and $\mathrm{Al}$, such as the formation of a $\mathrm{Li}-\mathrm{Al}$ oxide at the interfaces. This phenomenon would explain the improved stability of the samples upon exposure to air as well as the higher density of the films, as it hinders the out-diffusion of $\mathrm{Li}$ as well as reduces the grain's surface energy during annealing. The higher excess of $\mathrm{Li}$ present in the Al:LLZO film after annealing (see Table $S 1$ ), in comparison to the pristine film prepared with the same excess $\mathrm{Li}$, also supports this conclusion.

Spatially resolved quantification using energy-dispersive $\mathrm{X}$ ray spectroscopy (EDX) of Al-substituted LLZO pellets obtained by Cheng et al. ${ }^{55}$ also provides evidence of a tendency of $\mathrm{Al}$ to segregate at the grain boundaries. Pesci et al. ${ }^{56}$ also investigated the inhomogeneous distribution of $\mathrm{Al}$ along grain boundaries of Al:LLZO pellets employing a similar FIB-ToF-SIMS technique. This phenomenon has also been recently reported by Wachter-Welz et al. ${ }^{57}$ and linked to the wide distribution of conductivities measured in a set of $\mathrm{Al}$ :LLZO pellets prepared in the same conditions.

We can conclude that, besides the role in stabilizing the cubic phase by creating $\mathrm{Li}$ vacancies, $\mathrm{Al}$ incorporated to LLZO thin films tends to accumulate on the grain boundaries, where it acts as a sintering agent and hinders the out-diffusion of $\mathrm{Li}$ during annealing. Moreover, the passivation layer that forms at the interfaces limits the $\mathrm{H}^{+} / \mathrm{Li}^{+}$exchange mechanism, increasing the air stability of the films.

3.2.2. Crystalline Phase. $\mathrm{Al}^{3+}$ is one of the most common supervalent ions employed in stabilizing LLZO. This element is able to partially occupy the Li sites in the LLZO lattice and generate additional $\mathrm{Li}^{+}$vacancies. These additional vacancies are responsible for the stabilization of the high-temperature cubic phase at lower temperatures and the improved ionic conductivity. However, besides the effect on the crystalline phase, the substitutional element may also play a role in the densification of the LLZO thin films and the stability of the compound in the presence of moisture and $\mathrm{CO}_{2}$.

To investigate the overall impact of $\mathrm{Al}$ substitution in LLZO thin films, Al-incorporated LLZO (Al:LLZO) films were compared to the best Al-free (pristine LLZO) samples. The total amount of added $\mathrm{Al}$ was set to $1 \mathrm{~mol}$ p.f.u. of LLZO, in order to provide enough $\mathrm{Al}$ to stabilize the cubic phase. Studies have suggested a threshold of 0.2 moles of $\mathrm{Al}$ p.f.u. ${ }^{58}$ However, in our case given the limited annealing temperature and the multilayer deposition approach, the amount of $\mathrm{Al}$ in the asdeposited film had to be increased substantially to guarantee the incorporation of enough $\mathrm{Al}$ to the LLZO grains.

The XRD patterns acquired during the in situ annealing shown in Figure 7 a show the evolution of the phase from the amorphous state at room temperature until the full crystallization into cubic LLZO at $700{ }^{\circ} \mathrm{C}$. At about $200{ }^{\circ} \mathrm{C}$, some peaks start to appear at angles around $2 \theta=30^{\circ}$. These peaks can be assigned to precursor phases like $\mathrm{ZrO}_{2}, \mathrm{Li}_{6} \mathrm{Zr}_{2} \mathrm{O}_{7}$, and $\mathrm{La}_{2} \mathrm{O}_{3}$. At $500{ }^{\circ} \mathrm{C}$, tetragonal LLZO first appears, and at around $550{ }^{\circ} \mathrm{C}$ it undergoes a phase transition from tetragonal to cubic phase. Above $650{ }^{\circ} \mathrm{C}$ the LLZO peaks reach their maximum intensity, indicating a complete crystallization. The XRD measurement at $700{ }^{\circ} \mathrm{C}$ reveals a fully cubic LLZO phase. The presence of $\mathrm{Al}$ in the form of amorphous oxides cannot be determined from the XRD measurements, but it is 
a
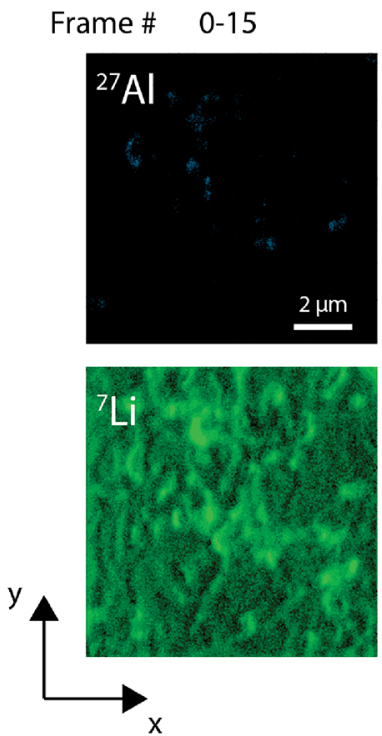

b

$\mathrm{x}(\mu \mathrm{m}) \quad 2.5-3.0$
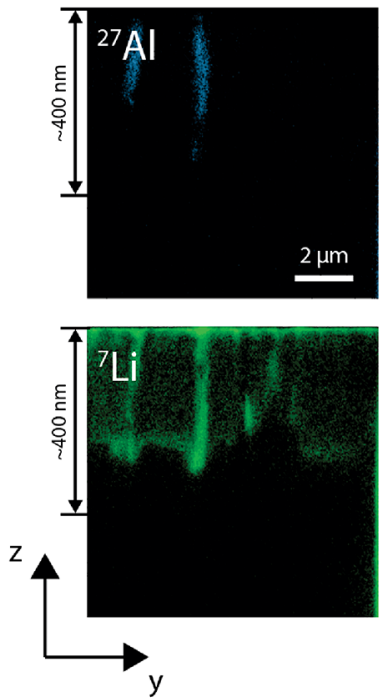

c

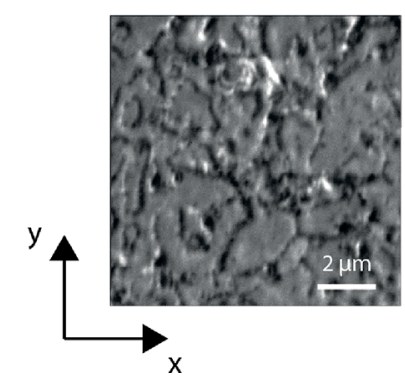

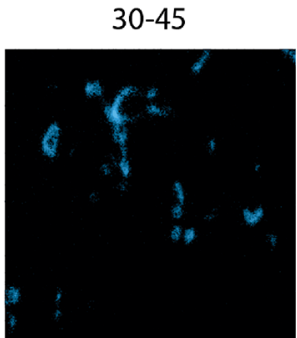

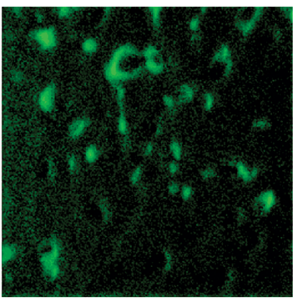

$3.5-4.0$
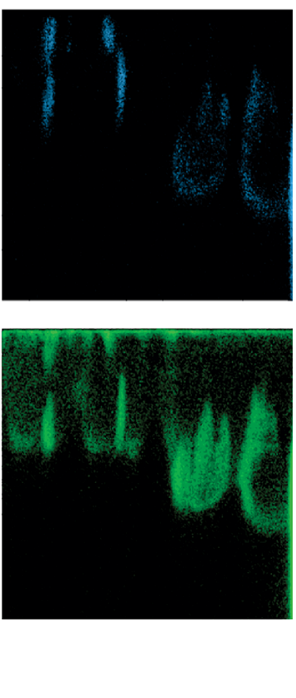

$60-75$
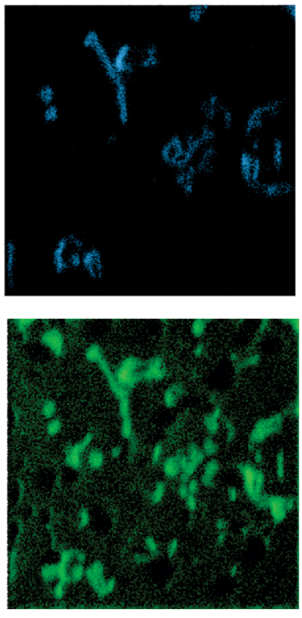

$4.5-5.0$
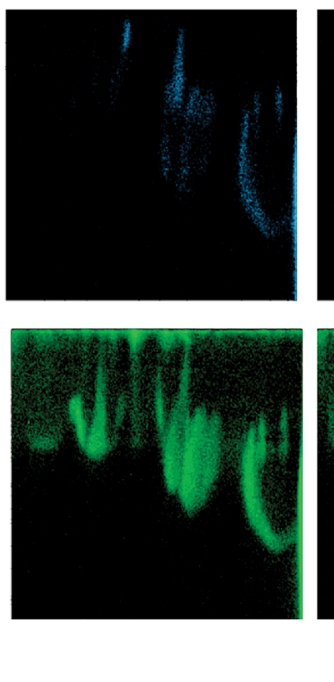

90-105
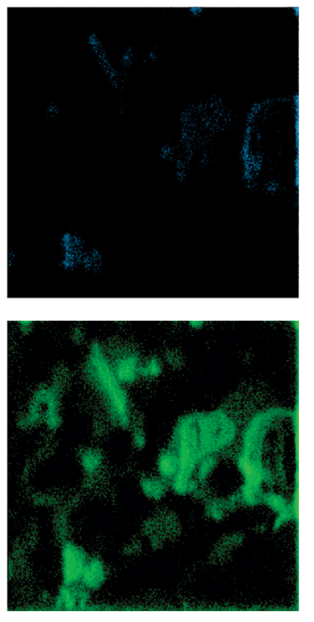

$5.5-6.0$
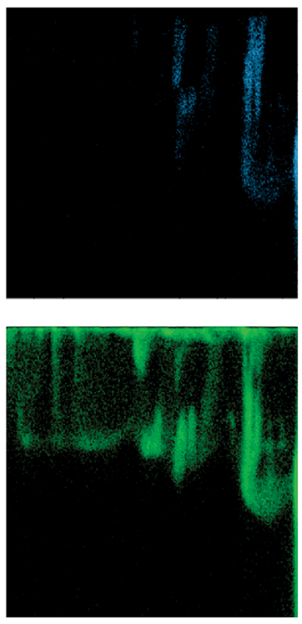

30

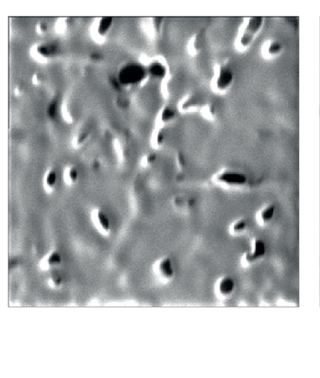

60

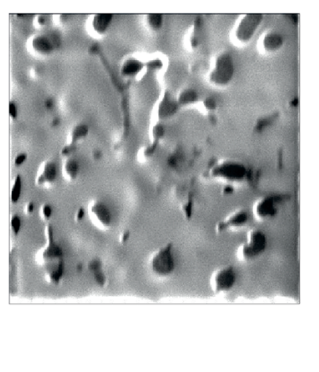

90

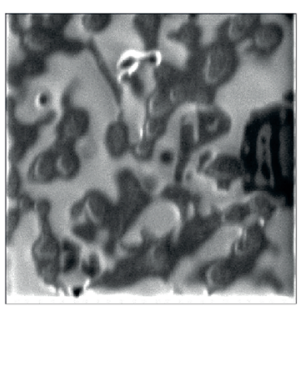

$120-135$
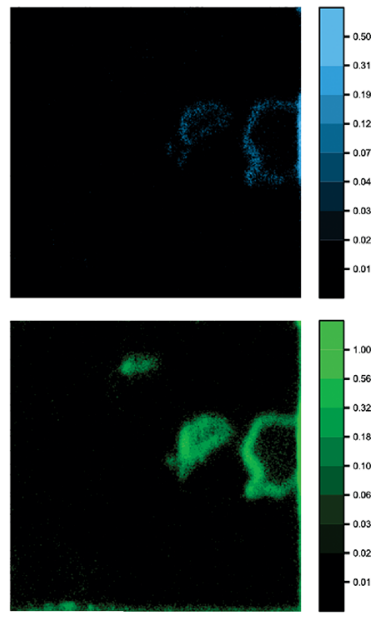

$6.5-7.0$
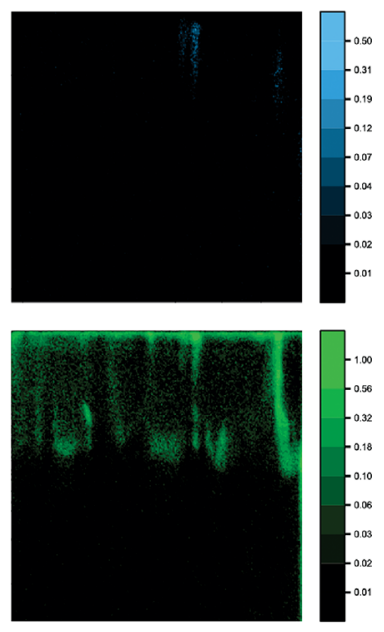

120

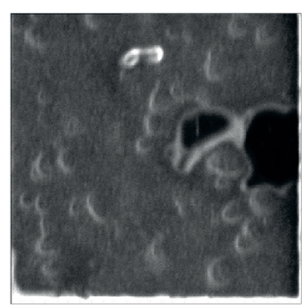

Figure 6. Representation of elemental structure of the Al-incorporated LLZO film obtained using a FIB-TOF-SIMS technique. (a) Top and (b) side views of ${ }^{7} \mathrm{Li}$ and ${ }^{27} \mathrm{Al}$ signals. (c) Top-view secondary-electron (SE) micrographs obtained during the FIB sputtering steps. Description in the text.

likely that the excess $\mathrm{Al}$ accumulates at the grain interfaces in this form.

Figure $7 \mathrm{~b}$ shows the XRD diffraction patterns of the postannealed pristine LLZO and Al-substituted LLZO (Al:LLZO) films. XRD patterns of cubic (ICSD 422259) and tetragonal (ICSD 246817) LLZO phases were used as reference for phase quantification and lattice constants determination using Rietveld refinements. The pristine LLZO film used as a reference presents a prominent tetragonal phase (76(2)\% tetragonal LLZO and 24(2)\% cubic LLZO). 

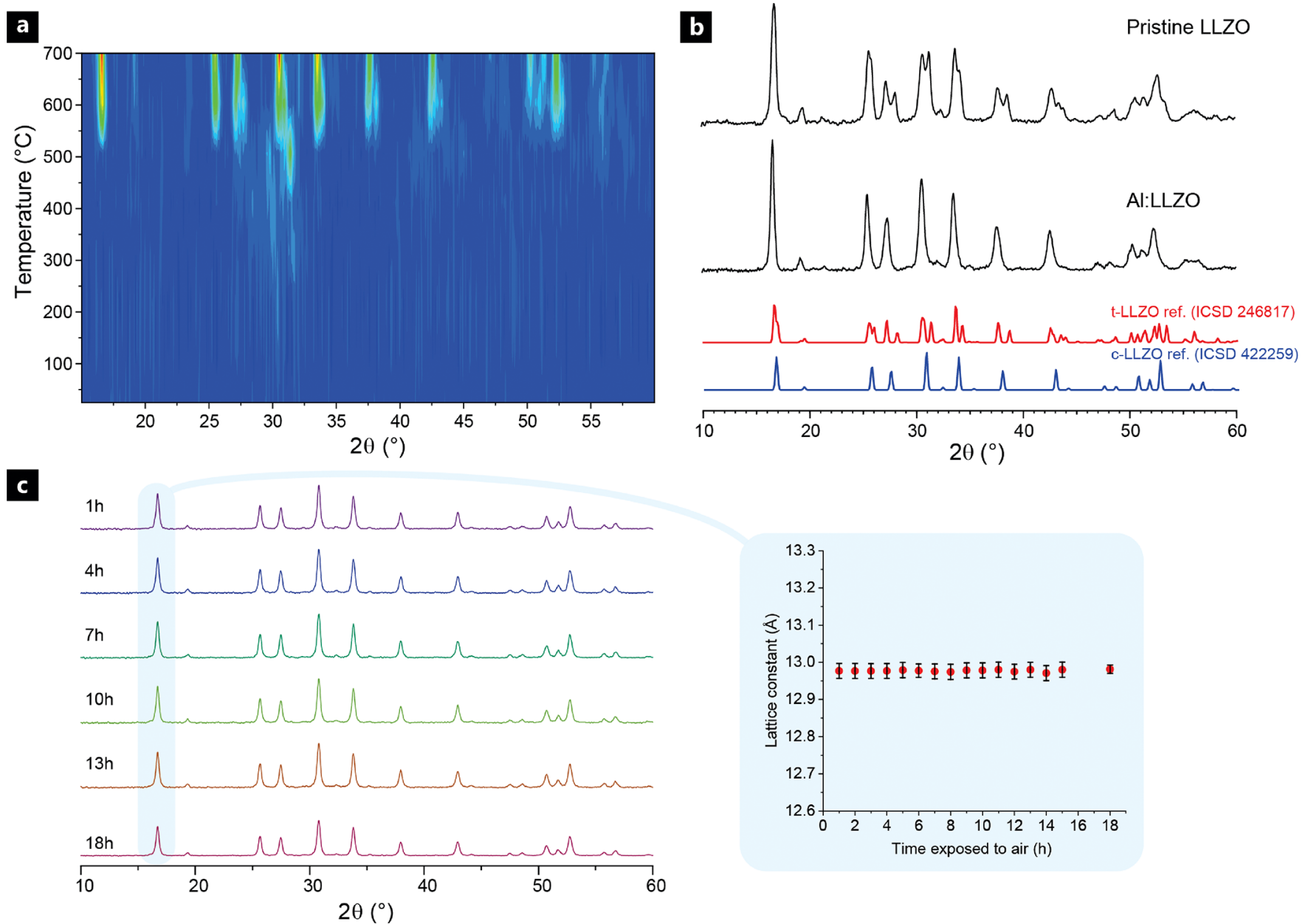

Figure 7. (a) Color map plot of the ambient in situ GI-XRD measurement of an Al:LLZO sample during the annealing process, starting at RT and heating up to $700^{\circ} \mathrm{C}$. (b) GI-XRD diffraction patterns of the pristine LLZO and the Al:LLZO samples after postannealing. Reference patterns of tetragonal LLZO (ICSD 246817) and cubic LLZO (ICSD 422259) are included. (c) GI-XRD patterns of the Al:LLZO sample exposed to air over $18 \mathrm{~h}$, measured in $1 \mathrm{~h}$ steps and a final measurement of $3 \mathrm{~h}$, and plot of the refined lattice constant of the cubic LLZO phase extracted from these XRD patterns.

The residual cubic phase present in the unsubstituted LLZO appears due to the $\mathrm{Li}^{+} / \mathrm{H}^{+}$exchange degradation mechanism described in the previous section. By contrast, the Al-doped samples show a predominant cubic phase (87(3)\% cubic LLZO and 13(3)\% tetragonal LLZO). The residual tetragonal phase can be explained as a result of an incomplete diffusion of Al throughout the film.

Figure $7 \mathrm{c}$ shows the LLZO XRD patterns measured over 18 $\mathrm{h}$ ( $1 \mathrm{~h}$ per scan for the 15 first scans and $3 \mathrm{~h}$ for the last scan) of an Al:LLZO sample exposed to air. Rietveld refinements of the patterns do not reveal any relevant change in phases and lattice constants during the exposure to air. Figure $7 \mathrm{c}$ also shows the refined cubic LLZO lattice constant over time. After $18 \mathrm{~h}$ of exposure to air, the lattice constant remains stable at 12.98(1) Å. This value is in good agreement with previous reports for Al-substituted LLZO, 55,59 which provides evidence that the phase achieved is the desired high-temperature cubic phase, and not the $\mathrm{H}^{+}$-stabilized cubic phase previously described. Unlike the pristine LLZO thin films, Al:LLZO thin films show improved air stability, at least for the time spans investigated.

3.2.3. Li-Ion Conductivity. The results of temperaturedependent impedance measurements, performed following the same approach used with the pristine LLZO samples, were fitted using the same equivalent circuit previously described. The Nyquist and Bode plots of the measured data and the fitting for the Al:LLZO sample annealed at atmospheric pressure are shown in Figure 8a. The fitted parameters can be found in Table S3. Figure $8 \mathrm{~b}$ shows the Arrhenius plot of the $\mathrm{Al}:$ LLZO sample in comparison to the best pristine LLZO sample. The effective ionic conductivity at RT of the Al:LLZO sample is $1.94(6) \times 10^{-5} \mathrm{~S} \mathrm{~cm}^{-1}$, and the fitted activation energy is $0.481(3) \mathrm{eV}$.

In comparison to the pristine LLZO films, one can observe that an improvement in the effective ionic conductivity is achieved through the incorporation of Al. The value of 1.94(6) $\times 10^{-5} \mathrm{~S} \mathrm{~cm}^{-1}$ is higher than any of the previously reported conductivities in sputtered LLZO thin films (excluding the measurements carried out on conductive substrates by Lobe et al. $\left.^{32}\right)$. However, this effective ionic conductivity still lags about 1 order of magnitude behind the best conductivities reported in highly dense $\mathrm{Al}:$ LLZO pellets processed at temperatures above $1000{ }^{\circ} \mathrm{C} .^{58}$

The activation energy improves only very slightly with respect to the pristine samples. Theoretical calculations estimate an energy barrier of $\sim 0.1-0.3 \mathrm{eV}$ for $\mathrm{Li}^{+}$conduction in bulk cubic LLZO. ${ }^{48}$ Experimental measurements in Al- 
a
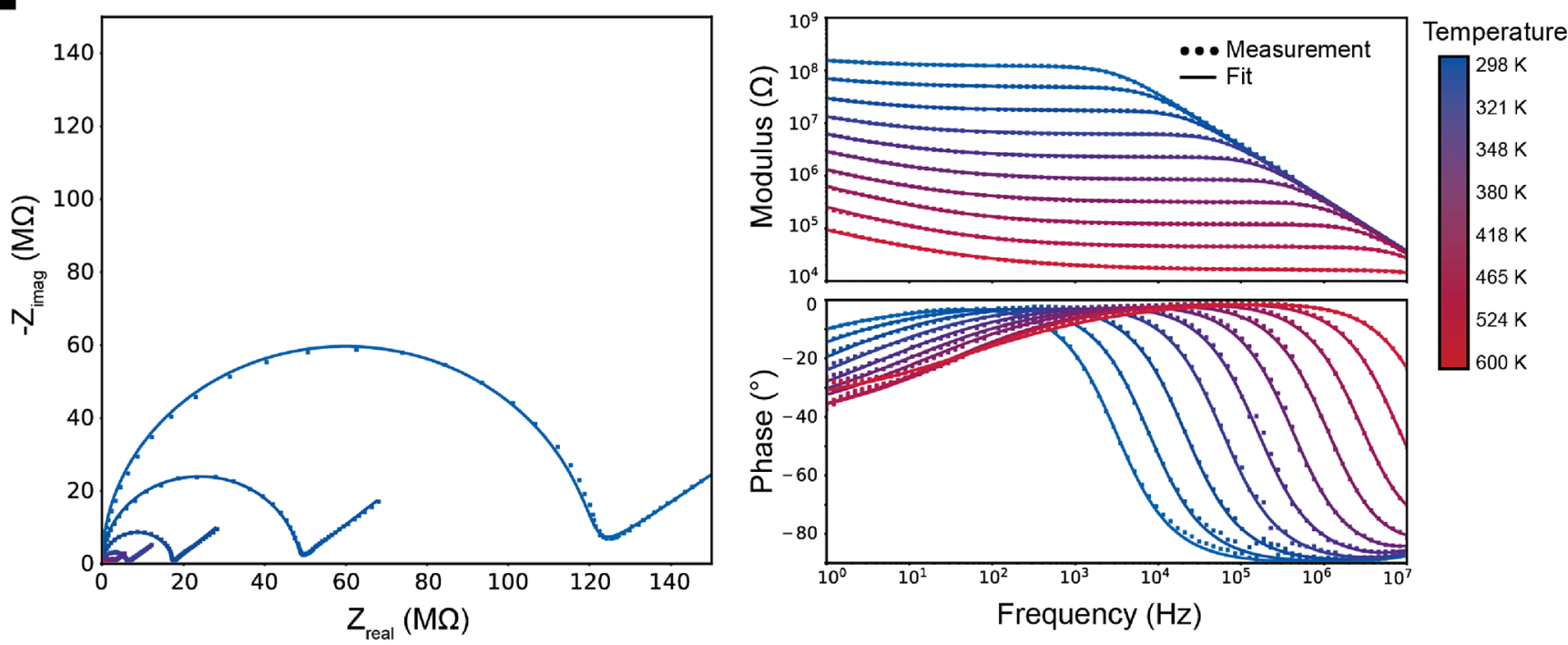

b

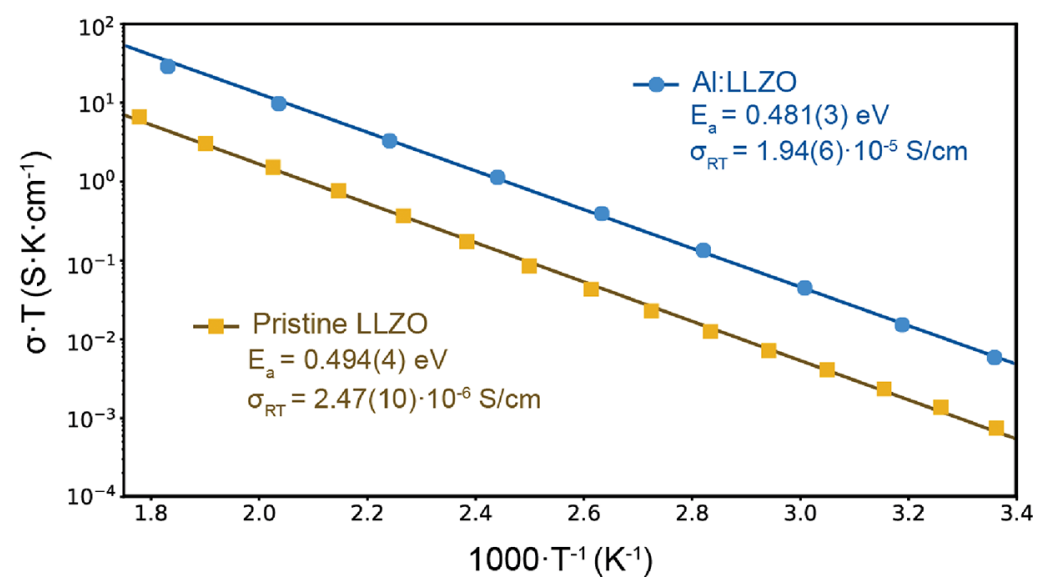

Figure 8. (a) Nyquist plot and Bode plot of the impedance spectroscopy data measured and fitted at temperatures ranging from 298 to $600 \mathrm{~K}$ on the Al:LLZO sample. (b) Arrhenius plots of the effective ionic conductivity of the Al:LLZO and pristine LLZO samples.

substituted LLZO pellets have demonstrated values as good as $0.26 \mathrm{eV},{ }^{58}$ in good agreement with the theoretical predictions.

To further investigate the ionic transport in the LLZO thin films, we also analyzed the complex electric modulus following the formalism developed by Almond and West ${ }^{60}$ (see Supporting Information for more details on the calculations). By using this quantity, the contribution from the low-frequency tail due to the electrode polarization and other interfacial effects can be effectively minimized. ${ }^{60}$ In this sense, it allows us to better distinguish hidden time constants in the Nyquist plot.

The imaginary parts of the electric modulus $M_{\text {imag }}$ obtained from the complex impedance data of both samples are respectively plotted in Figure S7a,b. On both plots only a single peak is observable for all the temperatures, indicating that the charge carrier transport is characterized by a single Maxwell time constant $\left(\tau=\epsilon_{0} \epsilon_{\mathrm{r}} / \sigma, \epsilon_{0}\right.$, where $\epsilon_{\mathrm{r}}$ is the vacuum permittivity, $\tau=1 /\left(2 \pi f_{\max }\right)$ the relative permittivity, and $\sigma$ the conductivity). The frequency at which the imaginary part of the modulus is maximum can be related to this time constant by $f_{\max }$.

Figure S7c,d shows the imaginary part of the electric modulus normalized to $M_{\text {imag,max }}$ and to the maximum of the imaginary part of the modulus $n=1-0.7=0.3$. One can observe that the slope of the lower frequencies in both samples (with and without $\mathrm{Al}$ ) is close to 1 , which indicates an ideal nondispersive long-range conduction as predicted by Debye theory. ${ }^{60}$ However, the plots show some asymmetry in the high-frequency region. In this region the slope is about 0.7 , which can be related to a dispersive exponent of $f_{\max }$. This dispersion may be a consequence of the polycrystallinity of the material and the polarization at the electrodes.

The frequency at which the imaginary part of the electric modulus is maximized also follows a thermally activated behavior, similar to the ionic conductivity. Figure S7e shows the Arrhenius plots of $\mathrm{Li}^{+}$for each sample. The fitted activation energies of the pristine LLZO and Al:LLZO films are 0.491(4) and $0.485(4) \mathrm{eV}$, respectively. These values are very similar to each other despite the different crystalline phases present in each sample. This reveals that in both cases the ionic transport is dominated by a similar conduction mechanism. The fact that the conductivities at room temperature present an order of magnitude difference may indicate that other factors beside the stabilization of the highly conductive phase play a role in the conductivity. We suggest these factors are the film density and air-induced protonation of the LLZO films. The incorporation of $\mathrm{Al}$ successfully enhances the film densification and improves 
the stability against air, which leads to an improvement of the conductivity by reducing the tortuosity of the conduction pathways, the increase in the charge carrier density (reduced Li-loss during annealing and $\mathrm{Li}^{+} / \mathrm{H}^{+}$exchange upon exposure to air), and the reduction of the interfacial resistances due to the growth of $\mathrm{Li}_{2} \mathrm{CO}_{3}$.

3.3. Deposition of LLZO Films on $\mathrm{LiCoO}_{2}$. In order to demonstrate the feasibility of employing this processing approach on a real battery architecture, we deposited Al:LLZO films on top of a half-cell stack consisting of a $\mathrm{Ni}-\mathrm{Al}-\mathrm{Cr}$ current collector film and a thin film $\mathrm{LiCoO}_{2}$ cathode. Details on the current collector and the cathode films are described by Filippin et al. ${ }^{61}$ To reduce the interdiffusivity of $\mathrm{Co}$, La, and $\mathrm{Zr}$ between the cathode and the electrolyte during the postannealing step, a $25 \mathrm{~nm}$ layer of $\mathrm{LiNbO}_{3}$ was introduced as a diffusion barrier.

Figure 9a shows the SEM cross-section of the half-cell stack with the crystallized Al:LLZO film on top. The same density
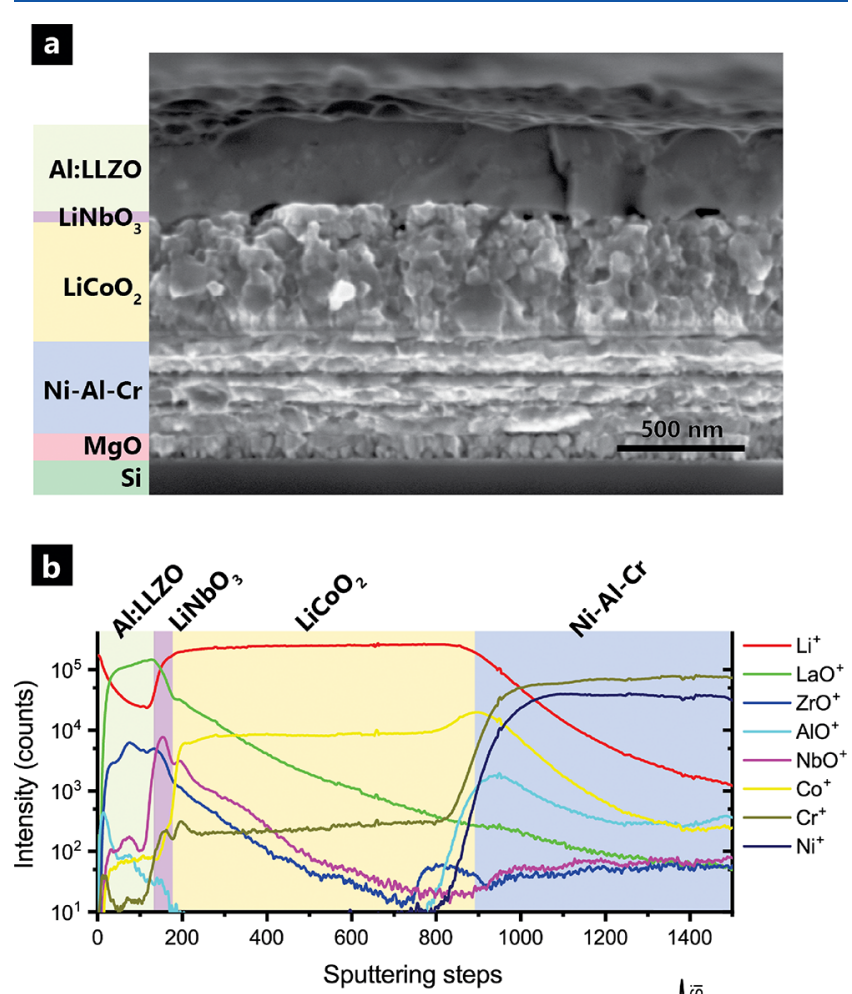

c

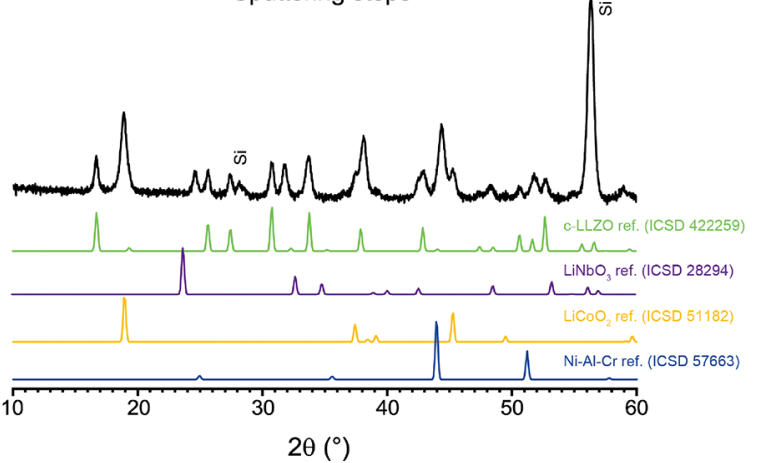

Figure 9. (a) SEM cross-section image of a half-cell stack ( $\mathrm{Si} / \mathrm{MgO}$ / $\mathrm{Ni}-\mathrm{Al}-\mathrm{Cr} / \mathrm{LiCoO}_{2} / \mathrm{LiNbO}_{3} / \mathrm{Al}$ :LLZO). (b) ToF-SIMS depth profile of the half-cell stack. (c) XRD pattern of the half-cell stack, including the reference patterns of cubic $\mathrm{LLZO}, \mathrm{LiCoO}_{2}$, and the $\mathrm{Ni}-$ $\mathrm{Al}-\mathrm{Cr}$ superalloy. and homogeneity of the LLZO film previously observed on $\mathrm{MgO}$ substrates are also achieved when deposited on a cathode material. Also, the ToF-SIMS measurement in Figure $9 \mathrm{~b}$ demonstrates that a sharp interface is present between the cathode and the electrolyte materials. As seen in the XRD pattern shown in Figure 9c, the high-temperature cubic LLZO phase is obtained after postannealing. The incorporation of a $\mathrm{LiNbO}_{3}$ interlayer seems to prevent the chemical reactions between the LLZO film and the cathode material that have been previously reported by Vardar et al. ${ }^{62}$ Our future efforts will be focused on the fabrication of full battery stacks by depositing metallic lithium films as anode and investigating the electrochemical properties of such thin-film batteries.

\section{CONCLUSIONS}

The fabrication of dense and highly ionic-conductive lithium garnet films for all-solid-state lithium batteries is demonstrated by employing a cosputtering method followed by a postannealing step at $700{ }^{\circ} \mathrm{C}$, which is substantially lower than the typical temperatures employed in processing powder LLZO into thick pellets. This method offers flexibility for the incorporation of excess lithium and phase stabilizers in the asdeposited LLZO films and can be transferred to the processing of other electrolyte materials.

Excess of $\mathrm{Li}$ in the sputtered films needs to be effectively regulated to compensate $\mathrm{Li}$ loss during the processing steps and achieve a crystalline and dense film. Too low an amount of $\mathrm{Li}$ in the as-deposited films leads to the formation of lithiumdeficient nonconductive phases after postannealing, whereas a high excess of $\mathrm{Li}$ promotes the formation of porosity and inhomogeneities in the film as a consequence of $\mathrm{Li}$ evaporation. A porous morphology not only harms the ionic conductivity but also has a detrimental effect on the air stability due to the higher surface to volume ratio.

Incorporation of $\mathrm{Al}$ in the films not only acts as cubic phase stabilizer but also plays a role as sintering agent during the annealing of the films, which leads to a significant improvement in the density without requiring higher annealing temperatures. The superior compactness and the formation of an $\mathrm{Al}$-rich passivation layer on the grain surfaces improve the stability of the films upon exposure to $\mathrm{H}_{2} \mathrm{O}$ and $\mathrm{CO}_{2}$.

We demonstrate that following this approach dense and highly conductive LLZO films can be fabricated at low processing temperatures, with an effective ionic conductivity of up to $1.94 \times 10^{-5} \mathrm{~S} \mathrm{~cm}^{-1}$. This thin film electrolyte can be potentially integrated in an all-solid-state battery architecture, combining metallic $\mathrm{Li}$ as anode and a high-potential cathode material. In order to prove this, we show that the LLZO films investigated on $\mathrm{MgO}$ substrates can be deposited on a cathode material like $\mathrm{LiCoO}_{2}$ retaining their phase and morphological properties.

\section{ASSOCIATED CONTENT}

\section{Supporting Information}

The Supporting Information is available free of charge at https://pubs.acs.org/doi/10.1021/acsaem.9b01387.

Cross-sectional SEM images before and after annealing, ICP-MS measurement data, XRD measurements of films annealed with different pressures, XRD measurements of pristine films after different exposure times to air, ToFSIMS depth profiles, EDX measurement of the LLZO surface, effective ionic conductivity calculations, fitted 
equivalent circuit parameters, FIB-ToF-SIMS measurement information and supplementary figures, and complex electric modulus analysis (PDF)

\section{AUTHOR INFORMATION}

\section{Corresponding Author}

*E-mail: jordi.sastrepellicer@empa.ch. Phone: +41 5876561 10.

\section{ORCID $\odot$}

Jordi Sastre: 0000-0003-0866-0911

Tzu-Ying Lin: 0000-0002-3428-9944

Agnieszka Priebe: 0000-0003-0425-246X

Enrico Avancini: 0000-0003-1309-1290

Stephan Buecheler: 0000-0003-0942-9965

\section{Author Contributions}

${ }^{\S}$ J.S. and T.-Y.L. contributed equally to this work.

\section{Notes}

The authors declare no competing financial interest.

\section{ACKNOWLEDGMENTS}

This work was supported by the Swiss National Science Foundation (Grant 200021_172764) and Taiwan's Ministry of Science and Technology (Grant 106-2917-I-564-001-A1). We acknowledge the Laboratory for Advanced Analytical Technologies at Empa for the ICP-MS measurements, the Laboratory for Energy Conversion Materials for the access to $\mathrm{XRD}$ equipment, and the Laboratory for Nanoscale Materials Science for the access to ToF-SIMS equipment.

\section{REFERENCES}

(1) Tarascon, J.-M.; Armand, M. Issues and Challenges Facing Rechargeable Lithium Batteries. Nature 2001, 414, 359-367.

(2) Armand, M.; Tarascon, J.-M. Building Better Batteries. Nature 2008, 451, 652-657.

(3) Dunn, B.; Kamath, H.; Tarascon, J.-M. Electrical Energy Storage for the Grid: A Battery of Choices. Science 2011, 334, 928-935.

(4) Janek, J.; Zeier, W. G. A Solid Future for Battery Development. Nature Energy 2016, 1, 16141.

(5) Murugan, R.; Thangadurai, V.; Weppner, W. Fast Lithium Ion Conduction in Garnet-Type $\mathrm{Li}_{7} \mathrm{La}_{3} \mathrm{Zr}_{2} \mathrm{O}_{12}$. Angew. Chem., Int. Ed. 2007, 46, 7778-7781.

(6) Li, Y.; Han, J.-T.; Wang, C.-A.; Vogel, S. C.; Xie, H.; Xu, M.; Goodenough, J. B. Ionic Distribution and Conductivity in Lithium Garnet $\mathrm{Li}_{7} \mathrm{La}_{3} \mathrm{Zr}_{2} \mathrm{O}_{12}$. J. Power Sources 2012, 209, 278-281.

(7) Deviannapoorani, C.; Dhivya, L.; Ramakumar, S.; Murugan, R. Lithium Ion Transport Properties of High Conductive Tellurium Substituted $\mathrm{Li}_{7} \mathrm{La}_{3} \mathrm{Zr}_{2} \mathrm{O}_{12}$ Cubic Lithium Garnets. J. Power Sources 2013, 240, 18-25.

(8) Yi, E.; Wang, W.; Kieffer, J.; Laine, R. M. Key Parameters Governing the Densification of Cubic- $\mathrm{Li}_{7} \mathrm{La}_{3} \mathrm{Zr}_{2} \mathrm{O}_{12} \mathrm{Li}^{+}$Conductors. J. Power Sources 2017, 352, 156-164.

(9) Zhu, Y.; He, X.; Mo, Y. Origin of Outstanding Stability in the Lithium Solid Electrolyte Materials: Insights from Thermodynamic Analyses Based on First-Principles Calculations. ACS Appl. Mater. Interfaces 2015, 7, 23685-23693.

(10) Richards, W. D.; Miara, L. J.; Wang, Y.; Kim, J. C.; Ceder, G. Interface Stability in Solid-State Batteries. Chem. Mater. 2016, 28, 266-273.

(11) Thompson, T.; Yu, S.; Williams, L.; Schmidt, R. D.; GarciaMendez, R.; Wolfenstine, J.; Allen, J. L.; Kioupakis, E.; Siegel, D. J.; Sakamoto, J. Electrochemical Window of the Li-Ion Solid Electrolyte $\mathrm{Li}_{7} \mathrm{La}_{3} \mathrm{Zr}_{2} \mathrm{O}_{12}$. ACS Energy Letters 2017, 2, 462-468.

(12) Ni, J. E.; Case, E. D.; Sakamoto, J. S.; Rangasamy, E.; Wolfenstine, J. B. Room Temperature Elastic Moduli and Vickers
Hardness of Hot-Pressed LLZO Cubic Garnet. J. Mater. Sci. 2012, 47, 7978-7985.

(13) Yu, S.; Schmidt, R. D.; Garcia-Mendez, R.; Herbert, E.; Dudney, N. J.; Wolfenstine, J. B.; Sakamoto, J.; Siegel, D. J. Elastic Properties of the Solid Electrolyte $\mathrm{Li}_{7} \mathrm{La}_{3} \mathrm{Zr}_{2} \mathrm{O}_{12}$ (LLZO). Chem. Mater. 2016, 28, 197-206.

(14) Awaka, J.; Kijima, N.; Hayakawa, H.; Akimoto, J. Synthesis and Structure Analysis of Tetragonal $\mathrm{Li}_{7} \mathrm{La}_{3} \mathrm{Zr}_{2} \mathrm{O}_{12}$ with the GarnetRelated Type Structure. J. Solid State Chem. 2009, 182, 2046-2052.

(15) Buschmann, H.; Dölle, J.; Berendts, S.; Kuhn, A.; Bottke, P.; Wilkening, M.; Heitjans, P.; Senyshyn, A.; Ehrenberg, H.; Lotnyk, A.; Duppel, V.; Kienle, L.; Janek, J. Structure and Dynamics of the Fast Lithium Ion Conductor " $\mathrm{Li}_{7} \mathrm{La}_{3} \mathrm{Zr}_{2} \mathrm{O}_{12}$. Phys. Chem. Chem. Phys. 2011, $13,19378$.

(16) Wolfenstine, J.; Rangasamy, E.; Allen, J. L.; Sakamoto, J. High Conductivity of Dense Tetragonal $\mathrm{Li}_{7} \mathrm{La}_{3} \mathrm{Zr}_{2} \mathrm{O}_{12}$. J. Power Sources 2012, 208, 193-196.

(17) Kotobuki, M.; Song, S.; Chen, C.; Lu, L. Ceramic Electrolytes for All-Solid-State Li Batteries; World Scientific, 2017.

(18) Howard, M. A.; Clemens, O.; Kendrick, E.; Knight, K. S.; Apperley, D. C.; Anderson, P. A.; Slater, P. R. Effect of Ga Incorporation on the Structure and $\mathrm{Li}$ Ion Conductivity of $\mathrm{Li}_{7} \mathrm{La}_{3} \mathrm{Zr}_{2} \mathrm{O}_{12}$. Dalton Transactions 2012, 41, 12048-12053.

(19) Wolfenstine, J.; Ratchford, J.; Rangasamy, E.; Sakamoto, J.; Allen, J. L. Synthesis and High Li-Ion Conductivity of Ga-Stabilized Cubic $\mathrm{Li}_{7} \mathrm{La}_{3} \mathrm{Zr}_{2} \mathrm{O}_{12}$. Mater. Chem. Phys. 2012, 134, 571-575.

(20) Rettenwander, D.; Wagner, R.; Reyer, A.; Bonta, M.; Cheng, L.; Doeff, M. M.; Limbeck, A.; Wilkening, M.; Amthauer, G. Interface Instability of $\mathrm{Fe}$-Stabilized $\mathrm{Li}_{7} \mathrm{La}_{3} \mathrm{Zr}_{2} \mathrm{O}_{12}$ versus $\mathrm{Li}$ Metal. J. Phys. Chem. C 2018, 122, 3780-3785.

(21) Rawlence, M.; Filippin, A. N.; Wäckerlin, A.; Lin, T.-Y.; Cuervo-Reyes, E.; Remhof, A.; Battaglia, C.; Rupp, J. L. M.; Buecheler, S. Effect of Gallium Substitution on Lithium-Ion Conductivity and Phase Evolution in Sputtered $\mathrm{Li}_{7-3 x} \mathrm{Ga}_{x} \mathrm{La}_{3} \mathrm{Zr}_{2} \mathrm{O}_{1} 2$ Thin Films. ACS Appl. Mater. Interfaces 2018, 10, 13720-13728.

(22) Rawlence, M.; Garbayo, I.; Buecheler, S.; Rupp, J. L. M. On the Chemical Stability of Post-Lithiated Garnet Al-Stabilized $\mathrm{Li}_{7} \mathrm{La}_{3} \mathrm{Zr}_{2} \mathrm{O}_{12}$ Solid State Electrolyte Thin Films. Nanoscale 2016, 8, $14746-14753$.

(23) Loho, C.; Djenadic, R.; Bruns, M.; Clemens, O.; Hahn, H. Garnet-Type $\mathrm{Li}_{7} \mathrm{La}_{3} \mathrm{Zr}_{2} \mathrm{O}_{12}$ Solid Electrolyte Thin Films Grown by $-\mathrm{CO}_{2}$ Laser Assisted CVD for All-Solid-State Batteries. J. Electrochem. Soc. 2017, 164, A6131-A6139.

(24) Tadanaga, K.; Egawa, H.; Hayashi, A.; Tatsumisago, M.; Mosa, J.; Aparicio, M.; Duran, A. Preparation of Lithium Ion Conductive AlDoped $\mathrm{Li}_{7} \mathrm{La}_{3} \mathrm{Zr}_{2} \mathrm{O}_{12}$ Thin Films by a Sol-Gel Process. J. Power Sources 2015, 273, 844-847.

(25) Kazyak, E.; Chen, K.-H.; Wood, K. N.; Davis, A. L.; Thompson, T.; Bielinski, A. R.; Sanchez, A. J.; Wang, X.; Wang, C.; Sakamoto, J.; Dasgupta, N. P. Atomic Layer Deposition of the Solid Electrolyte Garnet $\mathrm{Li}_{7} \mathrm{La}_{3} \mathrm{Zr}_{2} \mathrm{O}_{12}$. Chem. Mater. 2017, 29, 3785-3792.

(26) Kalita, D.; Lee, S.; Lee, K.; Ko, D.; Yoon, Y. Ionic Conductivity Properties of Amorphous $\mathrm{Li}-\mathrm{La}-\mathrm{Zr}-\mathrm{O}$ Solid Electrolyte for Thin Film Batteries. Solid State Ionics 2012, 229, 14-19.

(27) Nong, J.; Xu, H.; Yu, Z.; Zhu, G.; Yu, A. Properties and Preparation of $\mathrm{Li}-\mathrm{La}-\mathrm{Ti}-\mathrm{Zr}-\mathrm{O}$ Thin Film Electrolyte. Mater. Lett. 2015, 154, 167-169.

(28) Tan, J.; Tiwari, A. Fabrication and Characterization of $\mathrm{Li}_{7} \mathrm{La}_{3} \mathrm{Zr}_{2} \mathrm{O}_{12}$ Thin Films for Lithium Ion Battery. ECS Solid State Lett. 2012, 1, Q57-Q60.

(29) Park, J. S.; Cheng, L.; Zorba, V.; Mehta, A.; Cabana, J.; Chen, G.; Doeff, M. M.; Richardson, T. J.; Park, J. H.; Son, J.-W.; Hong, W.S. Effects of Crystallinity and Impurities on the Electrical Conductivity of $\mathrm{Li}-\mathrm{La}-\mathrm{Zr}-\mathrm{O}$ Thin Films. Thin Solid Films 2015, 576, 55-60.

(30) Chen, R.-J.; Huang, M.; Huang, W.-Z.; Shen, Y.; Lin, Y.-H.; Nan, C.-W. Sol-Gel Derived Li-La-Zr-O Thin Films as Solid Electrolytes for Lithium-Ion Batteries. J. Mater. Chem. A 2014, 2, 13277. 
(31) Kim, S.; Hirayama, M.; Taminato, S.; Kanno, R. Epitaxial Growth and Lithium Ion Conductivity of Lithium-Oxide Garnet for an All Solid-State Battery Electrolyte. Dalton Transactions 2013, 42, 13112

(32) Lobe, S.; Dellen, C.; Finsterbusch, M.; Gehrke, H. G.; Sebold, D.; Tsai, C. L.; Uhlenbruck, S.; Guillon, O. Radio Frequency Magnetron Sputtering of $\mathrm{Li}_{7} \mathrm{La}_{3} \mathrm{Zr}_{2} \mathrm{O}_{12}$ Thin Films for Solid-State Batteries. J. Power Sources 2016, 307, 684-689.

(33) Pfenninger, R.; Struzik, M.; Garbayo, I.; Stilp, E.; Rupp, J. L. M. A Low Ride on Processing Temperature for Fast Lithium Conduction in Garnet Solid-State Battery Films. Nature Energy 2019, 4, 475-483.

(34) Zarabian, M.; Bartolini, M.; Pereira-Almao, P.; Thangadurai, V. $\mathrm{X}$-Ray Photoelectron Spectroscopy and AC Impedance Spectroscopy Studies of $\mathrm{Li}-\mathrm{La}-\mathrm{Zr}$-O Solid Electrolyte Thin Film $/ \mathrm{LiCoO}_{2}$ Cathode Interface for All-Solid-State Li Batteries. J. Electrochem. Soc. 2017, 164, A1133-A1139.

(35) Saccoccio, M.; Yu, J.; Lu, Z.; Kwok, S. C. T.; Wang, J.; Yeung, K. K.; Yuen, M. M. F.; Ciucci, F. Low Temperature Pulsed Laser Deposition of Garnet $\mathrm{Li}_{6.4} \mathrm{La}_{3} \mathrm{Zr}_{1.4} \mathrm{Ta}_{0.6} \mathrm{O}_{12}$ Films as All Solid-State Lithium Battery Electrolytes. J. Power Sources 2017, 365, 43-52.

(36) Huggins, R. A. Simple Method to Determine Electronic and Ionic Components of the Conductivity in Mixed Conductors a Review. Ionics 2002, 8, 300-313.

(37) Canepa, P.; Dawson, J. A.; Sai Gautam, G.; Statham, J. M.; Parker, S. C.; Islam, M. S. Particle Morphology and Lithium Segregation to Surfaces of the $\mathrm{Li}_{7} \mathrm{La}_{3} \mathrm{Zr}_{2} \mathrm{O}_{12}$ Solid Electrolyte. Chem. Mater. 2018, 30, 3019-3027.

(38) Kimura, H.; Asano, M.; Kubo, K. Thermochemical Study of the Vaporization of $\mathrm{Li}_{2} \mathrm{O}(c)$ by Mass Spectrometric Knudsen Effusion Method. J. Nucl. Mater. 1980, 92, 221-228.

(39) Sata, T. High-Temperature Vaporization of $\mathrm{Li}_{2} \mathrm{O}$ Component from Solid Solutionin $\mathrm{Li}_{x} \mathrm{Ni}_{1-\mathrm{x}} \mathrm{O}$ Air. Ceram. Int. 1998, 24, 53-59.

(40) Xie, H.; Li, Y.; Goodenough, J. B. Low-Temperature Synthesis of $\mathrm{Li}_{7} \mathrm{La}_{3} \mathrm{Zr}_{2} \mathrm{O}_{12}$ with Cubic Garnet-Type Structure. Mater. Res. Bull. 2012, 47, 1229-1232.

(41) Quinzeni, I.; Capsoni, D.; Berbenni, V.; Mustarelli, P.; Sturini, M.; Bini, M. Stability of Low-Temperature $\mathrm{Li}_{7} \mathrm{La}_{3} \mathrm{Zr}_{2} \mathrm{O}_{12}$ Cubic Phase: The Role of Temperature and Atmosphere. Mater. Chem. Phys. 2017, $185,55-64$

(42) Xie, H.; Alonso, J. A.; Li, Y.; Fernández-Díaz, M. T.; Goodenough, J. B. Lithium Distribution in Aluminum-Free Cubic $\mathrm{Li}_{7} \mathrm{La}_{3} \mathrm{Zr}_{2} \mathrm{O}_{12}$. Chem. Mater. 2011, 23, 3587-3589.

(43) Larraz, G.; Orera, A.; Sanjuán, M. L. Cubic Phases of GarnetType $\mathrm{Li}_{7} \mathrm{La}_{3} \mathrm{Zr}_{2} \mathrm{O}_{12}$ : The Role of Hydration. J. Mater. Chem. A 2013, $1,11419-11428$

(44) Toda, S.; Ishiguro, K.; Shimonishi, Y.; Hirano, A.; Takeda, Y.; Yamamoto, O.; Imanishi, N. Low Temperature Cubic Garnet-Type $\mathrm{CO}_{2}$-Doped $\mathrm{Li}_{7} \mathrm{La}_{3} \mathrm{Zr}_{2} \mathrm{O}_{12}$. Solid State Ionics 2013, 233, 102-106.

(45) Sharafi, A.; Yu, S.; Naguib, M.; Lee, M.; Ma, C.; Meyer, H. M.; Nanda, J.; Chi, M.; Siegel, D. J.; Sakamoto, J. Impact of Air Exposure and Surface Chemistry on $\mathrm{Li}-\mathrm{Li}_{7} \mathrm{La}_{3} \mathrm{Zr}_{2} \mathrm{O}_{12}$ Interfacial Resistance. J. Mater. Chem. A 2017, 5, 13475-13487.

(46) Matsui, M.; Takahashi, K.; Sakamoto, K.; Hirano, A.; Takeda, Y.; Yamamoto, O.; Imanishi, N. Phase Stability of a Garnet-Type Lithium Ion Conductor $\mathrm{Li}_{7} \mathrm{La}_{3} \mathrm{Zr}_{2} \mathrm{O}_{12}$. Dalton Trans 2014, 43, 10191024.

(47) Sharafi, A.; Kazyak, E.; Davis, A. L.; Yu, S.; Thompson, T.; Siegel, D. J.; Dasgupta, N. P.; Sakamoto, J. Surface Chemistry Mechanism of Ultra-Low Interfacial Resistance in the Solid-State Electrolyte Li7La3Zr2O12. Chem. Mater. 2017, 29, 7961-7968.

(48) Meier, K.; Laino, T.; Curioni, A. Solid-State Electrolytes: Revealing the Mechanisms of Li-Ion Conduction in Tetragonal and Cubic LLZO by First-Principles Calculations. J. Phys. Chem. C 2014, $118,6668-6679$.

(49) Il'ina, E. A.; Andreev, O. L.; Antonov, B. D.; Batalov, N. N. Morphology and Transport Properties of the Solid Electrolyte $\mathrm{Li}_{7} \mathrm{La}_{3} \mathrm{Zr}_{2} \mathrm{O}_{12}$ Prepared by the Solid-State and Citrate-Nitrate Methods. J. Power Sources 2012, 201, 169-173.
(50) Daniel, S.; Chaudhury, M. K.; Chen, J. C. Fast Drop Movements Resulting from the Phase Change on a Gradient Surface. Science 2001, 291, 633-636.

(51) Jin, Y.; McGinn, P. J. Al-Doped $\mathrm{Li}_{7} \mathrm{La}_{3} \mathrm{Zr}_{2} \mathrm{O}_{12}$ Synthesized by a Polymerized Complex Method. J. Power Sources 2011, 196, 86838687.

(52) Zhang, Y.; Chen, F.; Tu, R.; Shen, Q.; Zhang, L. Field Assisted Sintering of Dense Al-Substituted Cubic Phase $\mathrm{Li}_{7} \mathrm{La}_{3} \mathrm{Zr}_{2} \mathrm{O}_{12}$ Solid Electrolytes. J. Power Sources 2014, 268, 960-964.

(53) Li, Y.; Wang, C.-A.; Xie, H.; Cheng, J.; Goodenough, J. B. High Lithium Ion Conduction in Garnet-Type $\mathrm{Li}_{6} \mathrm{La}_{3} \mathrm{ZrTaO}_{12}$. Electrochem. Commun. 2011, 13, 1289-1292.

(54) Yi, E.; Wang, W.; Kieffer, J.; Laine, R. M. Flame Made Nanoparticles Permit Processing of Dense, Flexible, Li+ Conducting Ceramic Electrolyte Thin Films of Cubic-Li7La3Zr2O12 (c-LLZO). J. Mater. Chem. A 2016, 4, 12947-12954.

(55) Cheng, L.; Park, J. S.; Hou, H.; Zorba, V.; Chen, G.; Richardson, T.; Cabana, J.; Russo, R.; Doeff, M. Effect of Microstructure and Surface Impurity Segregation on the Electrical and Electrochemical Properties of Dense Al-Substituted $\mathrm{Li}_{7} \mathrm{La}_{3} \mathrm{Zr}_{2} \mathrm{O}_{12}$. J. Mater. Chem. A 2014, 2, 172-181.

(56) Pesci, F. M.; Brugge, R. H.; Hekselman, A. K. O.; Cavallaro, A.; Chater, R. J.; Aguadero, A. Elucidating the Role of Dopants in the Critical Current Density for Dendrite Formation in Garnet Electrolytes. J. Mater. Chem. A 2018, 6, 19817-19827.

(57) Wachter-Welzl, A.; Kirowitz, J.; Wagner, R.; Smetaczek, S.; Brunauer, G.; Bonta, M.; Rettenwander, D.; Taibl, S.; Limbeck, A.; Amthauer, G.; Fleig, J. The Origin of Conductivity Variations in AlStabilized $\mathrm{Li}_{7} \mathrm{La}_{3} \mathrm{Zr}_{2} \mathrm{O}_{12}$ Ceramics. Solid State Ionics 2018, 319, $203-$ 208.

(58) Rangasamy, E.; Wolfenstine, J.; Sakamoto, J. The Role of Al and $\mathrm{Li}$ Concentration on the Formation of Cubic Garnet Solid Electrolyte of Nominal Composition $\mathrm{Li}_{7} \mathrm{La}_{3} \mathrm{Zr}_{2} \mathrm{O}_{12}$. Solid State Ionics 2012, 206, 28-32.

(59) Awaka, J.; Takashima, A.; Kataoka, K.; Kijima, N.; Idemoto, Y.; Akimoto, J. Crystal Structure of Fast Lithium-Ion-Conducting Cubic $\mathrm{Li}_{7} \mathrm{La}_{3} \mathrm{Zr}_{2} \mathrm{O}_{12}$. Chem. Lett. 2011, 40, 60-62.

(60) Almond, D. P.; West, A. R. Impedance and Modulus Spectroscopy of "Real" Dispersive Conductors. Solid State Ionics $1983,11,57-64$.

(61) Filippin, A. N.; Lin, T.-Y.; Rawlence, M.; Zünd, T.; Kravchyk, K.; Sastre-Pellicer, J.; Haass, S. G.; Wäckerlin, A.; Kovalenko, M. V.; Buecheler, $\mathrm{S}$. Ni-Al-Cr Superalloy as High Temperature Cathode Current Collector for Advanced Thin Film Li Batteries. RSC Adv. 2018, 8, 20304-20313.

(62) Vardar, G.; Bowman, W. J.; Lu, Q.; Wang, J.; Chater, R. J.; Aguadero, A.; Seibert, R.; Terry, J.; Hunt, A.; Waluyo, I.; Fong, D. D.; Jarry, A.; Crumlin, E. J.; Hellstrom, S. L.; Chiang, Y.-M.; Yildiz, B. Structure, Chemistry, and Charge Transfer Resistance of the Interface between $\mathrm{Li}_{7} \mathrm{La}_{3} \mathrm{Zr}_{2} \mathrm{O}_{12}$ Electrolyte and $\mathrm{LiCoO}_{2}$ Cathode. Chem. Mater. 2018, 30, 6259-6276. 